\title{
An Overview of Solid-State Integrated Circuit Amplifiers in the Submillimeter-Wave and $\mathrm{THz}$ Regime
}

\author{
Lorene A. Samoska, Senior Member, IEEE
}

(Invited Paper)

\begin{abstract}
We present an overview of solid-state integrated circuit amplifiers approaching terahertz frequencies based on the latest device technologies which have emerged in the past several years. Highlights include the best reported data from heterojunction bipolar transistor (HBT) circuits, high electron mobility transistor (HEMT) circuits, and metamorphic HEMT (mHEMT) amplifier circuits. We discuss packaging techniques for the various technologies in waveguide modules and describe the best reported noise figures measured in these technologies. A consequence of THz transistors, namely ultra-low-noise at cryogenic temperatures, will be explored and results presented. We also present a short review of power amplifier technologies for the $\mathrm{THz}$ regime. Finally, we discuss emerging materials for THz amplifiers into the next decade.
\end{abstract}

Index Terms-Cryogenic electronics, HBTs, HEMTs, low-noise amplifiers, MMICs, submillimeter-wave, THz.

\section{INTRODUCTION}

$\mathbf{T}$ HIS paper attempts to present an overview of solid-state amplifiers approaching 1-THz operation [1]. Traditionally, solid-state integrated circuit amplifiers have been called MMICs, which stands for monolithic microwave (or millimeterwave) integrated circuit amplifiers, to indicate that the band of operation is the millimeter-wave band, with a wavelength between $1 \mathrm{~cm}$ and $1 \mathrm{~mm}$ (or 30-300 GHz in frequency). The term S-MMICs (for submillimeter-wave MMICs) is somewhat more descriptive, as it provides a lower limit for amplifier operation at a wavelength (in air) of $<1 \mathrm{~mm}$, which corresponds to $300 \mathrm{GHz}$ in frequency or higher. Today's amplifiers have easily surpassed the submillimeter-wave limit, and in only the past few years, solid-state integrated circuit amplifiers have reached operating frequencies of $400-700 \mathrm{GHz}$ and beyond. The field has been progressing very rapidly even in the past year alone, and it is

Manuscript received March 25, 2011; revised May 27, 2011; accepted May 27, 2011. Date of current version August 31, 2011. This work was carried out in part at the Jet Propulsion Laboratory, California Institute of Technology, under a contract with the National Aeronautics and Space Administration. This research was also supported in part by the W. M. Keck Institute for Space Studies.

The author is with the Jet Propulsion Laboratory, California Institute of Technology, Pasadena, CA 91109 USA (e-mail: Lorene.Samoska@jpl.nasa.gov).

Color versions of one or more of the figures in this paper are available online at http://ieeexplore.ieee.org.

Digital Object Identifier 10.1109/TTHZ.2011.2159558 very likely that the highly sought after true terahertz monolithic integrated circuit (TMIC) amplifier will soon become a reality.

In this paper, we make the distinction between solid-state amplifiers composed of semiconductor integrated circuits, and other terahertz amplifiers such as vacuum electronic devices (VEDs), which include backward wave oscillators (BWOs), travelling wave tubes (TWTs) extended interaction klystrons and oscillators (EIKs and EIOs), gyrotrons, and other vacuum-based sources, which have traditionally provided gain and high power at frequencies above $100 \mathrm{GHz}$ for many years. For a review on vacuum electronic sources, please see the paper by Booske [2] in this issue.

We first introduce solid-state integrated circuit amplifiers by describing the types of solid-state transistors, which have shown the potential for $\mathrm{THz}$ operation in Section II. These include high electron mobility transistors (HEMTs), metamorphic HEMTs (mHEMTs), which are HEMT devices grown on non-lattice-matched substrates, and heterojunction bipolar transistors (HBTs). In Section III, we describe the methods for testing amplifiers, using wafer probing for $S$-parameters and noise measurements. Subsequently, in Section IV, we present circuit results of MMICs and S-MMICs based on these devices, highlighting the best results from a number of leading institutions. We then describe methods for packaging the amplifiers in waveguide for practical use in Section $\mathrm{V}$ and discuss various types of waveguide transitions that have been successfully used to date. In Section VI, we review low-noise amplifier performance to date in terms of gain and noise figure as a function of frequency. Next, we discuss some interesting and useful consequences of S-MMICs and TMICs that are found to be emerging - particularly that the TMIC devices have record performance not only at $\mathrm{THz}$ frequencies, but also much lower frequencies. Exceptionally low-noise and cryogenic noise performance have been observed in the lower millimeter-wave frequencies with circuits designed from TMIC devices. We discuss the implications for power amplifiers in the $\mathrm{THz}$ regime in Section VII using traditional technologies (InP and GaAs), and emerging materials ( $\mathrm{GaN}$ ) for providing power in the submillimeter-wave regime. Additional emerging technologies for higher frequency amplification such as $\mathrm{SiGe}$ transistors and short gate-length CMOS will also be described in Section VIII. 


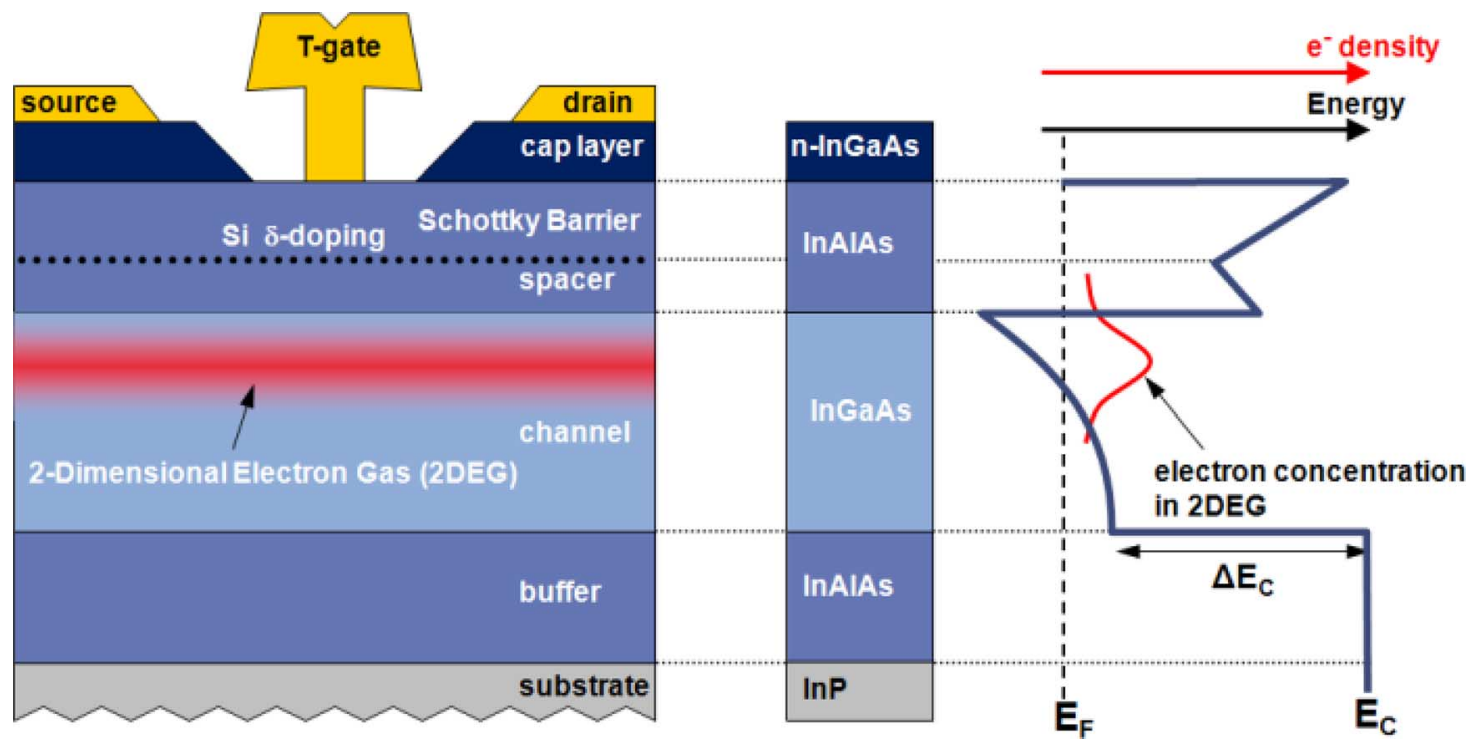

Fig. 1. Typical InP HEMT side view, layer structure, and side view energy band diagram, reproduced from [3].

\section{Solid-State Devices That Have Shown Potential FOR TERAHERTZ OPERATION}

\section{A. High Electron Mobility Transistors}

The HEMT is a heterostructure field-effect transistor made of semiconductors of different bandgaps. At the interfaces of the semiconductors, discontinuities occur that affect the relative alignment of the conduction and valence band offsets. One of the fastest materials systems for HEMTs involves the InP materials system, consisting of lattice matched $\mathrm{In}_{0.53} \mathrm{Ga}_{0.47} \mathrm{As}$ and $\mathrm{In}_{0.52} \mathrm{Al}_{0.48}$ As. The conduction band at the interface of these materials forms a triangular shaped potential well, which confines electrons in the well, in this case, in the layer of $\mathrm{In}_{0.53} \mathrm{Ga}_{0.47}$ As (Fig. 1). The electrons can move as a two-dimensional electron gas (2DEG), in which they can have exceptionally high mobilities compared to bulk material of the same composition. In order to have even higher electron mobilities, more indium may be added to the InGaAs layer. Since adding more indium makes the material more similar to InAs, which has a larger lattice constant, the InGaAs material becomes more progressively strained, such that only very thin layers can be successfully epitaxially grown without dislocations. Such InGaAs higher indium composition HEMTs are called pseudomorphic HEMTs. The most extreme case is a $100 \%$ In composition channel, made of InAs. The advantage of the higher indium content in the channel is that the electrons have higher mobility, which translates to the transistor having higher transconductance and higher gain at higher frequencies. In addition to scaling of the epitaxially grown layers, the HEMT is fabricated as shown in Fig. 1 [3], to have a gate contact in the shape of a $\mathrm{T}$. This helps to minimize the gate resistance when using a small gate length device. As device dimensions are decreased to improve the device speed, care must be taken to reduce parasitic resistances and capacitances in the device during the scaling. A simplified side view of a HEMT is shown in Fig. 1, with an energy band diagram shown at right, indicating the area of the 2DEG potential well.
Some of the key parameters that govern performance in an HEMT are the gate length, the gate-source capacitance, the transconductance, and saturation velocity. The transistor's speed is described by a figure of merit, $F t \sim g m /(2 \pi C g s)$, which is also equivalent to vsat/gate length. Thus, very simply, the transistor cutoff frequency will increase with increasing $g m$, or decreasing $C g s$ by making the device small, or both. To increase $g m$, one can make the channel material higher mobility (higher indium content), and reduce the gate length. The speed of a HEMT transistor can be measured by measuring the transistor's $S$-parameters with a network analyzer, and calculating the transistor's cutoff frequencies, $F t$, the current gain cutoff frequency, and $F \max$, the maximum frequency of oscillation. Both of these figures of merit are used to predict the highest speed of transistor operation. As an example, a recent InP HEMT transistor by NGC having a $35-\mathrm{nm}$ gate length, and two gate fingers each $20 \mu \mathrm{m}$ in width, has shown the following $F t$ property in Fig. 2, calculated and extrapolated from $H 21$ [4]. Fmax extrapolations in excess of $1 \mathrm{THz}$ are not uncommon with these devices.

\section{B. Metamorphic HEMTs}

Metamorphic HEMTs (mHEMTs) are HEMT devices that are epitaxially grown on non-lattice-matched substrates, e.g., an InP HEMT on a GaAs substrate. The advantages lie in the lower manufacturing costs of the GaAs substrates, better robustness of GaAs, and the larger wafer size available for production as compared to InP substrate materials. Good crystal quality is achieved with the use of a metamorphic transitional buffer layers between the GaAs substrate and the active device layers of the $\mathrm{InP} / \mathrm{InGaAs} / \mathrm{InAlAs}$ family to adapt the InP lattice constant to GaAs. Reference [5] provides an excellent overview of mHEMT manufacturers, device performance, and reliability. State-of-the-art mHEMT MMICs have GaAs substrates that are 2 mil thick and have gate lengths of $50 \mathrm{~nm}$ or less and thru-substrate vias as in InP HEMT MMICs. Recent highperformance mHEMTs have achieved $F \max >500 \mathrm{GHz}[6]$ 


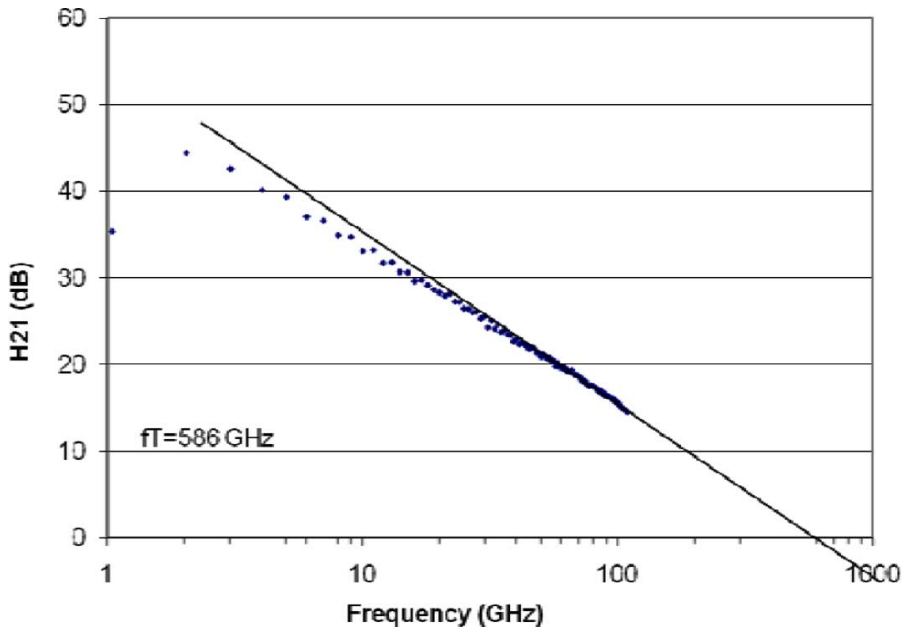

Fig. 2. NGC $35 \mathrm{~nm}$ InP HEMT extrapolated $F t$ data, from [4].

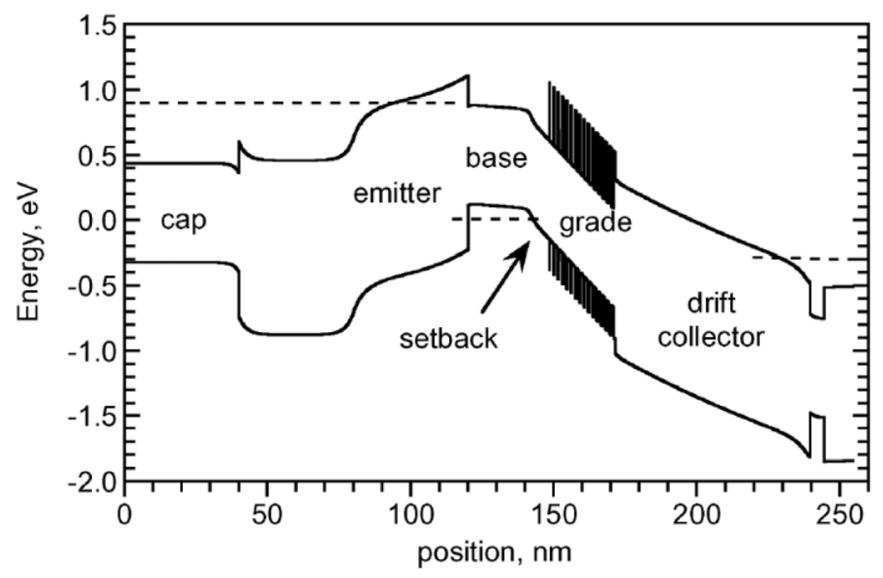

Fig. 3. HBT layer structure and band diagram, from [9]. Emitter cap is InGaAs, emitter material is InP, base is InGaAs, the grade is an InAlAs/InGaAs superlattice, and the collector is InP.

and $F t>500 \mathrm{GHz}$ [7]. The mHEMT cutoff frequencies are very similar to those obtained from HEMTs with the same gate lengths.

\section{Heterojunction Bipolar Transistors}

HBTs also consist of heterostructures of compound semiconductors, arranged to have a particular energy band diagram which allows for electrons to be injected from the emitter, travel quickly through the base layer and collector depletion region, and be collected in the subcollector region. Key parameters that govern RF performance include emitter and base junction widths, emitter $(R e x)$, base and collector $(R c)$ contact resistance, collector-base capacitance $(C c b)$, collector current density and transit time across the base $(T b)$, and collector $(T c)$. A basic equation for the current gain cutoff frequency is $F t=1 /(2 \pi((R e x+R c) C c b+(C b e+C c b) / g m+T b+T c))$, where $C b e$ is the base-emitter capacitance and $g m$ is the device transconductance. Power gain cutoff frequency $F \max$ is given by $F \max =F t /(8 \pi R b$, eff $* C c b$, eff $)$, where $R b b$, eff $* C c b$, eff represents the effective time constant for the distributed $R C$ network at the base-collector junction. An excellent resource for the basics of HBT operation is found in

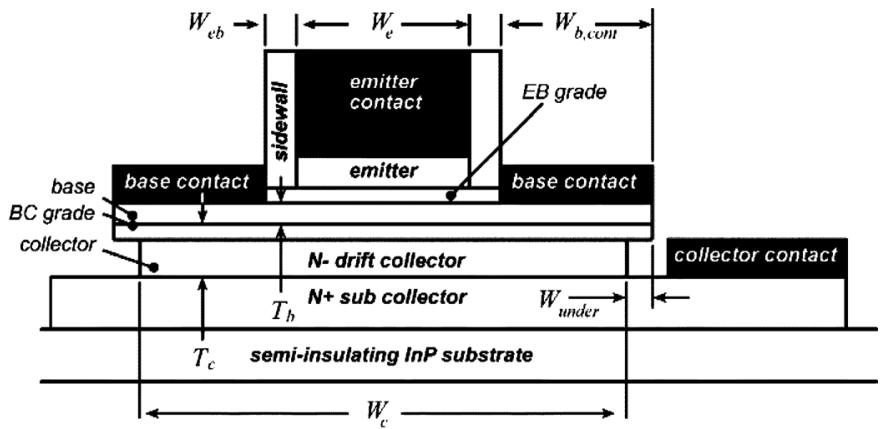

Fig. 4. Side view of InP HBT device (from [9]).

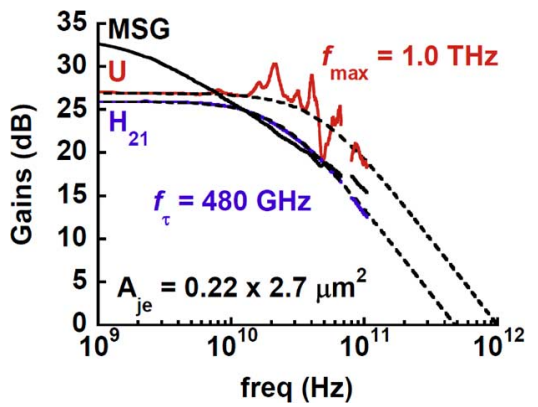

Fig. 5. Measured and extrapolated $H 21$ and Mason's unilateral gain for InP HBT's designed and fabricated at UCSB, having some of the highest figures of merit to date [11].

[8], and for high-performance HBTs, and the parameters that govern the potential for $\mathrm{THz}$ operation in [9] and [10].

A band diagram is shown in Fig. 3 [9], which indicates the epitaxial layer structure (and hence conduction and valence bands) versus position. A side view of a high-performance device is shown in Fig. 4 [9], where the key parameters that govern device speed are the emitter width, the base thickness and doping, and the base contact width, among other parameters. Some of the best reported results for $F t$ and $F \max$ are found in [11], where a single transistor has achieved $F \max \approx 1 \mathrm{THz}$ and simultaneously $F t \approx 480 \mathrm{GHz}$ (Fig. 5). Other notable results include $F t$ of nearly $400 \mathrm{GHz}$ and $F \max \approx 860 \mathrm{GHz}[12]$.

\section{Testing OF IC Amplifiers IN THE THz Regime}

Testing of S-MMIC or TMIC amplifier is accomplished primarily either on-wafer using waveguide wafer probes, or by packaging the S-MMIC in a waveguide housing. In the past decade, full two-port vector network analyzer measurements for waveguide have become possible up to $1 \mathrm{THz}$, through the efforts of small groups and commercial companies. OML, Inc. [13] has developed waveguide $S$-parameter VNA extenders compatible with commercial lower frequency network analyzers up to $500 \mathrm{GHz}$. These have been characterized and described in [14] and [15]. Wafer probes have been developed by GGB Industries [16], and on-wafer $S$-parameter calibration and characterization has been carried out in both the WR3 (220-325 GHz) and WR $2.2(325-500 \mathrm{GHz})$ waveguide bands [17], [18]. In addition to $S$-parameters, on-wafer noise measurements have been enabled by the wafer probes, and analysis and measured data on a $270-\mathrm{GHz}$ amplifier are presented 


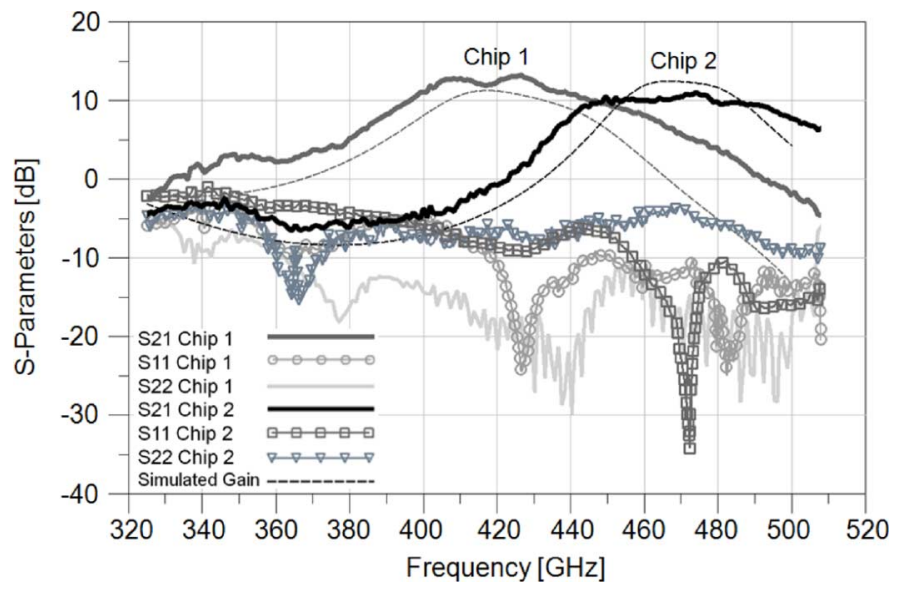

Fig. 6. On-wafer measured $S$-parameters from two chips having InAs channel HEMTs in NGC's $35-\mathrm{nm}$ process. The lower frequency chip uses two gate fingers each $15 \mu \mathrm{m}$ in width, while the higher frequency design uses two gate fingers each $10 \mu \mathrm{m}$ in width. Simulated $S 21$ gain curves are shown as dashed lines. For full simulated versus measured results on each chip, see [26].

in [19]. This method can be applied to much higher frequencies as long as wafer probes are available. On-wafer probes have also recently been developed at Cascade Microtech [20], and a system for on-wafer probing developed at the Fraunhofer Institute in [7]. In addition, Virginia Diodes [21] has built VNA extenders into the $\mathrm{THz}$ range. Micromachined on-wafer probes from $500-750 \mathrm{GHz}$ have been newly developed at the University of Virginia and show robustness and repeatability [22].

\section{THz MONOLITHIC INTEGRATED CIRCUIT AMPLIFIERS}

\section{A. THz Amplifiers Based on HEMTs: On Wafer Data}

In this section, we include on-wafer data from some of the best HEMT amplifiers to date. Common-source amplifiers are frequently used to design S-MMIC chips due to their simple layout structure and low noise performance. A common topology for HEMT MMIC amplifiers is to use a grounded coplanar waveguide medium with a 1- or 2-mil-thick InP substrate for the circuit design. This allows for the elimination of source inductance of a thru-substrate via (or pair of vias) on the source of the transistor, which would otherwise reduce the gain for a microstrip amplifier at the same frequency. By using a narrow ground-to-ground spacing for the coplanar waveguide ground planes which is approximately equal to the physical height of the HEMT, the source inductance is virtually eliminated. Microstrip amplifiers have been successfully employed up to $240 \mathrm{GHz}$ using source vias and 2-mil-thick substrates [23], though coplanar waveguide is used almost exclusively for higher frequencies. Grounded coplanar waveguide common-source amplifiers having three to four stages have been designed and measured on-wafer up to 500 $\mathrm{GHz}$ [24]-[26]. A pair of chips that utilize three stages of 35-nm InAs channel HEMTs with two gate fingers per device can cover the entire 390-500-GHz range [26], and the data are shown in Fig. 6.

Cascode amplifiers, in which a single-stage is comprised of two transistors, one having a common-source configuration and

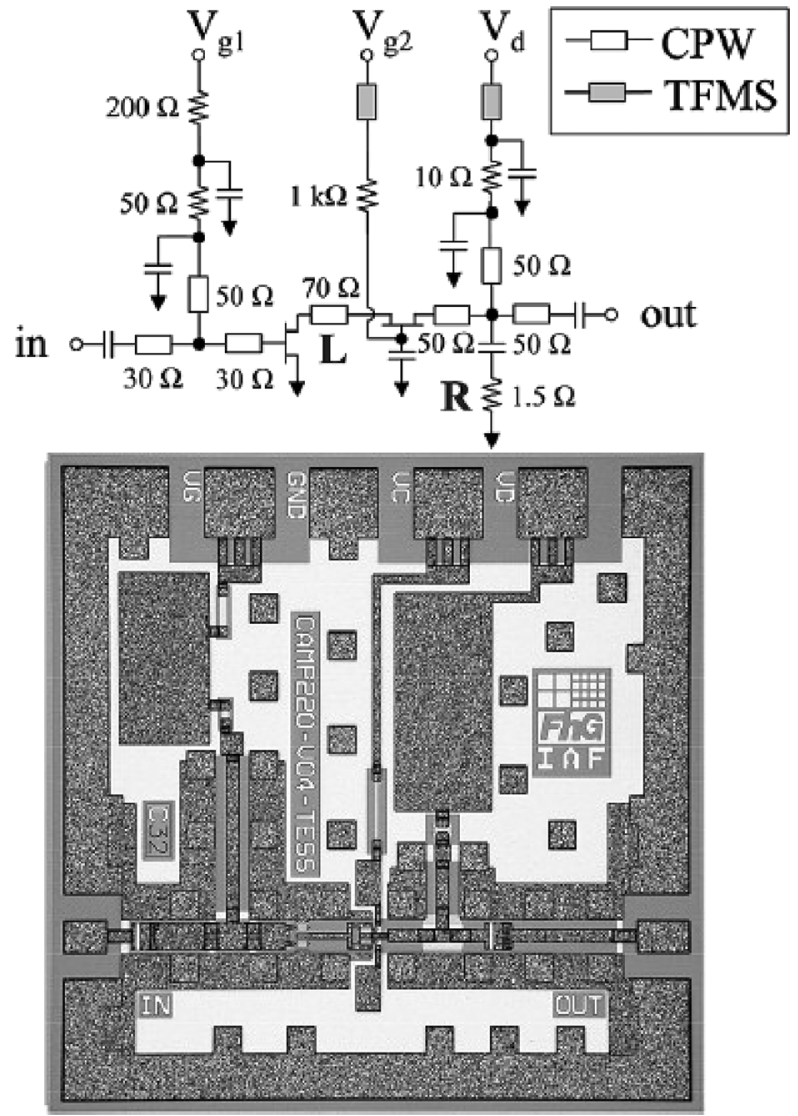

Fig. 7. Top: Schematic of cascode amplifier. Bottom: Chip photo of 220-GHz cascode MMIC [28].

the other having a common-gate configuration, have also gained favor due to their reduced Miller capacitance and consequently enhanced bandwidth. Successful implementation of the cascode configuration in high-frequency MMICs and S-MMICs can be found in [27] and [28]. A circuit schematic and chip photo is reproduced from [28] in Fig. 7. An example of a cascode amplifier having gain up to $600 \mathrm{GHz}$ is found in [29].

\section{B. THz Amplifiers Based on mHEMTs: On-Wafer Data}

Teledyne has developed the first successful microstrip mHEMT amplifiers up to at least $300 \mathrm{GHz}$, using a multiple-layer interconnect process with benzocyclobutene (BCB, epsilon $=2.7)$ as the low-loss intermetal dielectric. The BCB acts as the microwave substrate. This allows for a very compact design and more predictable modeling and electromagnetic simulation as compared to circuits with grounded coplanar waveguide elements, for which complete models do not exist in typical circuit tools (Agilent ADS), and which are more difficult to model with electromagnetic simulation tools. A photograph of a chip from this process is shown in Fig. 8 [6] and measured $S$-parameters in Fig. 9.

Researchers at the Fraunhofer Institute have also developed a 35-nm mHEMT process on 2-mil-thick GaAs [30]. The circuits are grounded coplanar waveguide circuits, similar to those reported for HEMT S-MMIC amplifiers. A chip photograph and measured $S$-parameter on-wafer data are shown in Figs. 10 and 11 [7]. The circuit employs four stages of mHEMTs with 


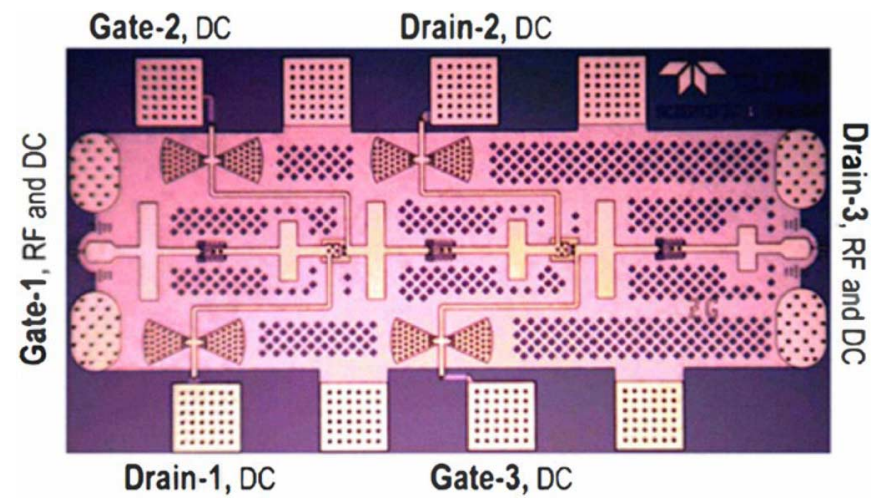

Fig. 8. Chip photograph of a three-stage 35-nm InP mHEMT amplifier with thin-film microstrip wiring environment, developed at Teledyne Scientific [6].

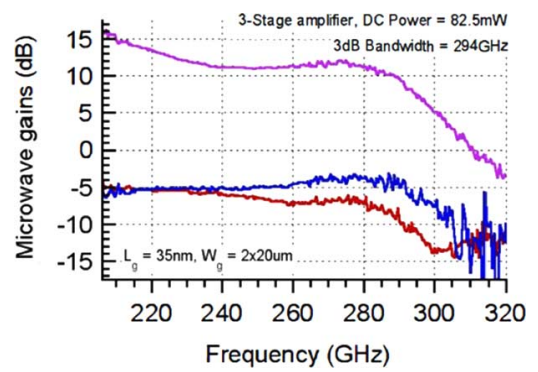

Fig. 9. Measured $S$-parameters for three-stage mHEMT amplifier from Fig. 8 [6].

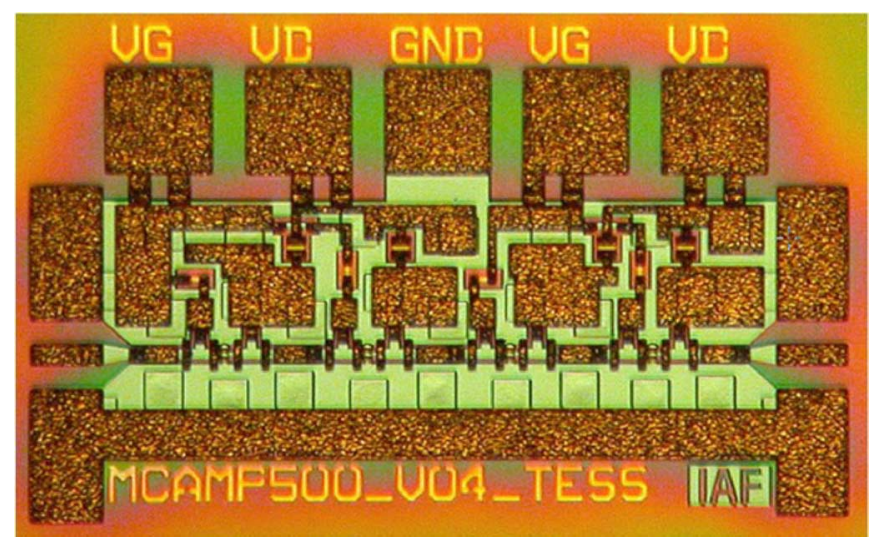

Fig. 10. Chip photograph of four-stage 460-GHz mHEMT amplifier S-MMIC [7].

$\mathrm{In}_{0.80} \mathrm{Ga}_{0.20}$ As channels and two gate fingers each $5 \mu \mathrm{m}$ in width and achieves a record $16 \mathrm{~dB}$ of gain at $460 \mathrm{GHz}$.

\section{THz Amplifiers Based on HBTs: MMICs and S-MMICs-On-Wafer Data}

HBT MMICs operating above $200 \mathrm{GHz}$ have recently made great strides in terms of performance. The topology of choice departs from the mHEMT and HEMT topology of grounded coplanar waveguide circuits on the original InP substrate.

Instead, HBT TMICs are using almost exclusively a microstrip wiring environment on a low loss $\mathrm{BCB}$ substrate. This enables more accurate device modeling with the use of microstrip models from circuit analyzers, while providing

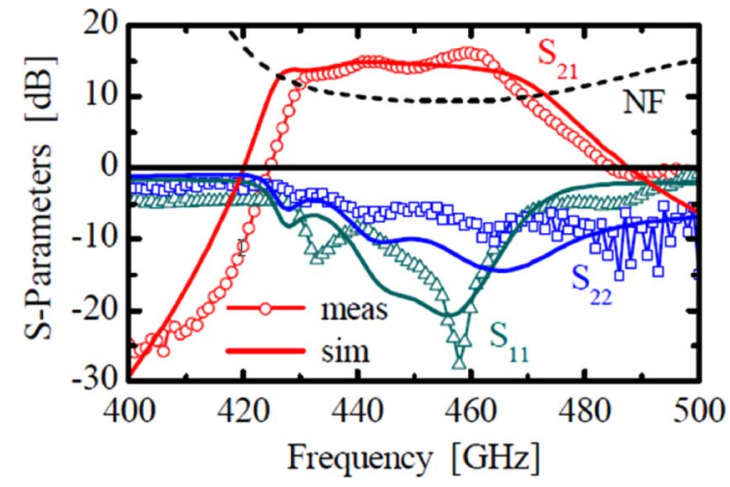

Fig. 11. On-wafer measured and simulated $S$-parameters of the $460-\mathrm{GHz}$ mHEMT S-MMIC amplifier. The dotted line is a simulated noise figure [7].

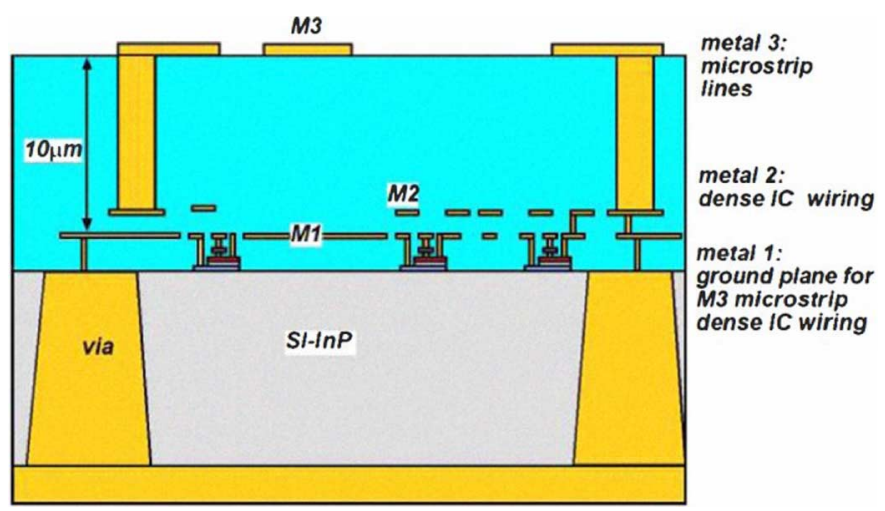

Fig. 12. IC wiring environment cross section showing the low loss $\mathrm{BCB}$ substrate above the InP substrate, and placement of microstrip lines and vias (from [31]).

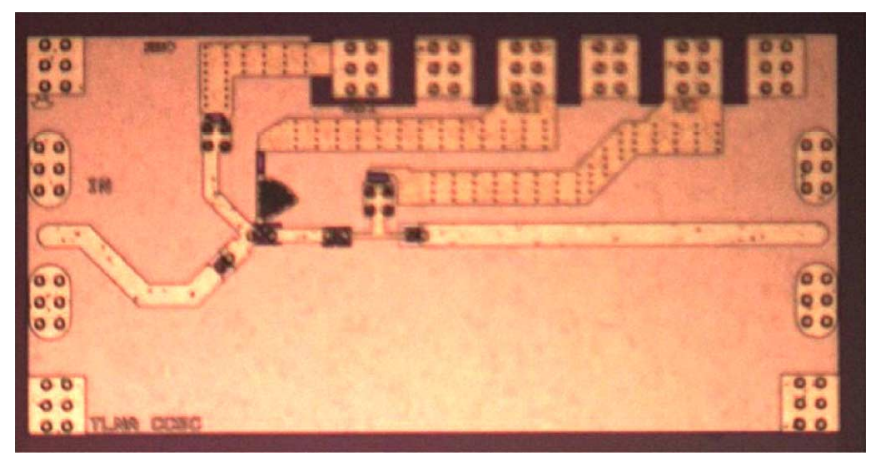

Fig. 13. Chip photograph of cascode InP HBT TMIC with microstrip lines on $10-\mu$ m-thick BCB substrate [31].

a low-loss wiring environment suited for $\mathrm{THz}$ applications. One such wiring environment is shown in Fig. 12 [31]. The BCB "substrate" material is spun onto the InP HBT wafer, and microstrip lines and vias are implemented in it, while the original InP substrate remains to add robustness to the chip. A InP HBT TMIC cascode circuit is shown in Fig. 13. Measured $S$-parameters of a two-cascode-stage chip from the same process are shown in Fig. 14, having more than $10 \mathrm{~dB}$ of gain per cascode stage at $320 \mathrm{GHz}$ [12]. Differential amplifier circuits were also designed in this process [32], [33], with one circuit having seven differential stages and a total of $25 \mathrm{~dB}$ of gain at $325 \mathrm{GHz}$ [33]. Other recent HBT MMIC results 


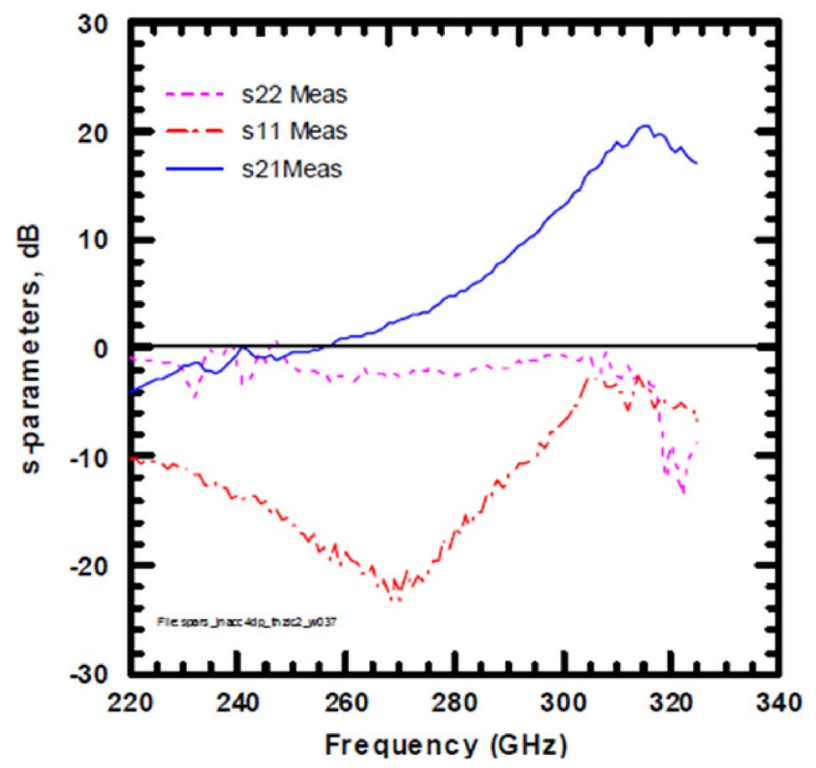

Fig. 14. $S$-parameters of a two-cascode stage HBT TMIC LNA circuit, using the BCB substrate. [12].

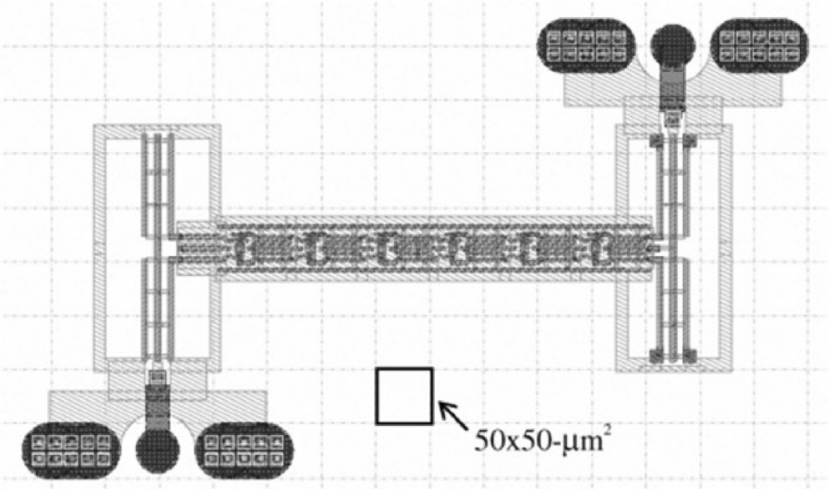

Fig. 15. Chip layout of 300-GHz differential HBT amplifier, from [32].

include $4.8 \mathrm{~dB}$ of gain at $324 \mathrm{GHz}$ [34], and $3.5 \mathrm{~dB}$ of gain for a single-stage amplifier at $255 \mathrm{GHz}$ [35].

\section{PACKAgING OF AmPlifiers For the THz REgime}

\section{A. Waveguide Packaging Using Hybrid Probes}

Traditional MMIC packaging, at least above $\sim 70 \mathrm{GHz}$, relies on converting the microstrip or coplanar waveguide mode in the MMIC to a convenient waveguide mode, for practical use with other waveguide components found at these frequencies. At frequencies below $300 \mathrm{GHz}$, this typically requires a separate transition circuit element to convert the microstrip mode to the waveguide mode, usually TE10. Waveguide probe transitions are made from a variety of materials, including commonly manufactured alumina (dielectric constant of 9.6) and quartz (dielectric constant of 3.8). The common E-plane probe (after [36]), where the substrate surface aligns along the direction of propagation of the waveguide is shown in Fig. 16. This configuration has been used successfully to mount MMIC chips up to

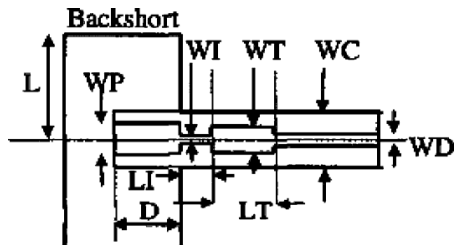

Fig. 16. From [35]: Common E-plane probe transition in the longitudinal configuration.

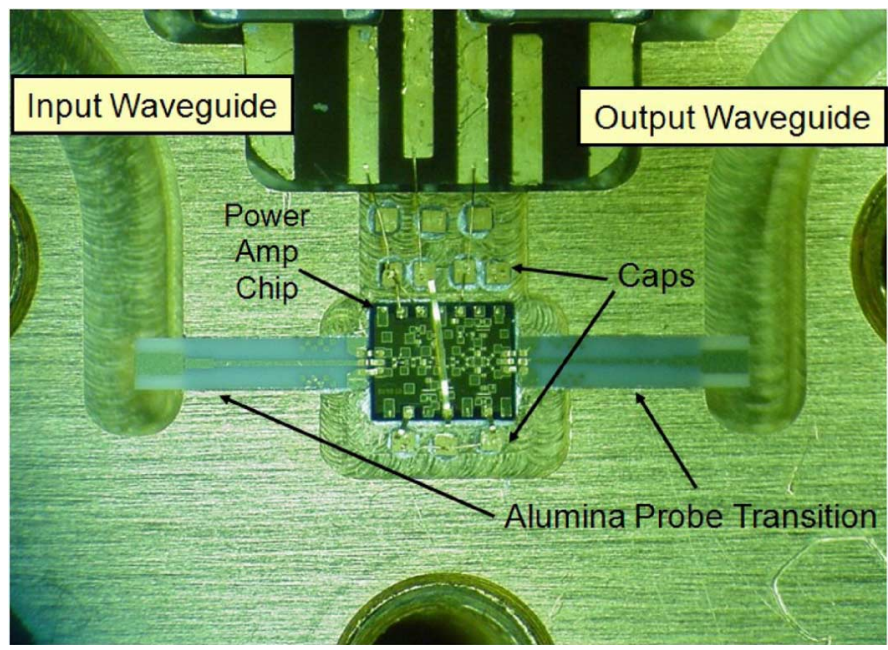

Fig. 17. Typical configuration used for mounting of MMIC chips in waveguide packages [37].

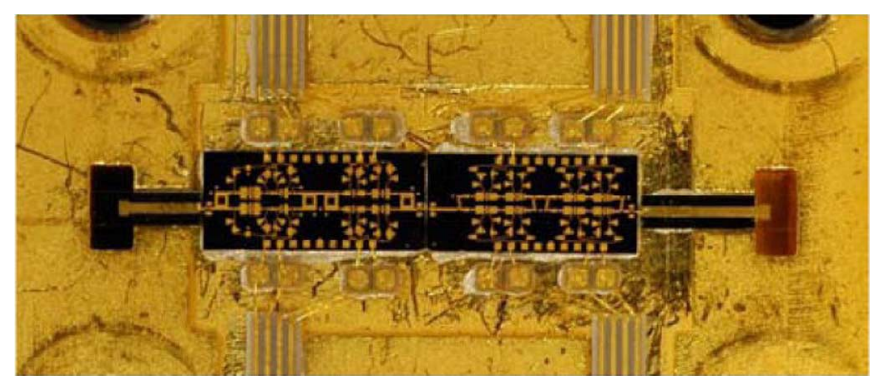

Fig. 18. G-band 20-mW InP HEMT module, showing broadside orientation of the probe [38].

at least $300 \mathrm{GHz}$ by wire bonding the MMIC to the microstrip line on the probe. A typical mounting configuration is shown in Fig. 17, where an alumina probe provides the mode conversion between the TE10 waveguide and a coplanar waveguide circuit, with a wirebond connecting between the MMIC and the microstrip probe [37]. Waveguide probes may also be mounted in other orientations, as demonstrated in Fig. 18, which shows a probe in a broadside configuration, also sometimes referred to as diving board configuration [38]. Very low loss transitions may be made this way due to short waveguide input or output sections possible in the overall package design. An excellent example of high performance quartz probes using traditional wirebonding is shown by Tessmann [39] in Fig. 19, with an amplifier module having gain of $20 \mathrm{~dB}$ up to $320 \mathrm{GHz}$. Vias were not used to transition between the grounded coplanar waveguide of the chip to the microstrip on the probe. 


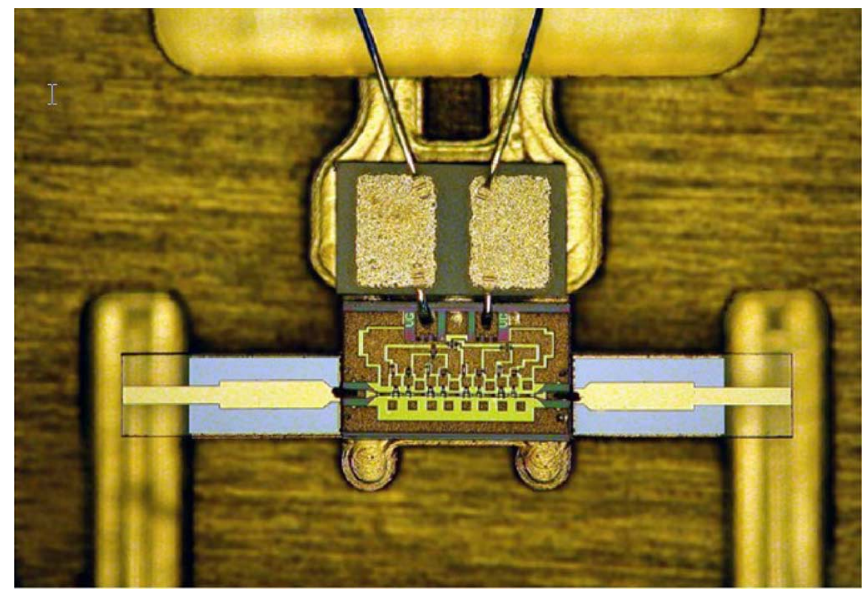

Fig. 19. Photo of 300-GHz mHEMT amplifier module using 2-mil-thick quartz E-plane probes [39].

\section{B. Waveguide Packaging Using Monolithic E-Plane Probes}

While an upper limit to the ability to successfully wirebond a hybrid probe to a MMIC has not been reached or published, we expect that eventually, at a high enough frequency, the wirebond inductance will cause sufficient mismatch to render the technique unsuccessful. Therefore, in recent years, attempts to integrate waveguide transitions monolithically on the MMICs have been studied and reported.

The first published attempt for integrating an E-plane probe with a MMIC amplifier was described by Weinreb in 1999 [40] and shown in Fig. 20. The initial design was constrained by the height of the MMIC chip, and therefore the amount of dielectric material in the waveguide was more than desired, based on the scaling rules developed in [36], and the integrated probe was not successfully implemented.

Full-bandwidth E-plane probes have not yet been demonstrated monolithically, most likely due to the constraints that typical MMIC amplifiers are fabricated on 2-mil-thick substrates with a dielectric constant of 12-13, and the chip height is constrained by the need for on-chip biasing networks which take up vertical space. Partial-bandwidth monolithically integrated probes, however, were demonstrated in 2008 with a radial rather than rectangular E-plane probe, following the work of Kooi and Chattopadhyay on radial probes for use in 400-500-GHz SIS mixer technology [41]. The design was chosen to achieve a desired bandwidth around an atmospheric window near $340 \mathrm{GHz}$, given the constraints of a MMIC with a 2-mil InP (high dielectric) substrate. The probe cavity was altered from the usual rectangular shape to improve the bandwidth and high-frequency performance. An S-MMIC with integrated radial probes is shown in Fig. 21, having over $14 \mathrm{~dB}$ of gain at $307 \mathrm{GHz}$ and operating until $340 \mathrm{GHz}$ [42].

Further refinements of the monolithic E-plane probe concept are being developed at Teledyne Scientific [12]. An HBT MMIC amplifier has been designed with integrated waveguide probes, where the entire chip has been etched out to have a nonrectangular shape. The probe area is substantially narrower than the MMIC, enabling higher frequency operation than is traditionally possible when using high dielectric InP substrates (Fig. 22).

\section{Waveguide Packaging With Monolithic Dipole Transitions}

A unique approach to packaging of S-MMIC amplifiers in waveguide was described in [43]. The coplanar waveguide mode of the S-MMIC is transferred to a coplanar slot mode and then to a dipole radiator, where the direction of propagation is in line with the direction of propagation of the waveguide. Fig. 23 shows the implementation for a $340-380-\mathrm{GHz}$ dipole transition operating with a 2-mil-thick InP substrate. Fig. 24 shows the back-to-back probes mounted in a waveguide, having a chip width substantially larger than that possible with the radial E-plane probe method. Amplifier modules having gain up to $390 \mathrm{GHz}$ have been measured using this concept [4]. Further improvements to this approach include the thinning of the substrate to 1 mil thickness, which has led to the first S-MMIC module operating at $480 \mathrm{GHz}$, shown in Fig. 25 [44], [45]. Additional improvements to the device technology and a cascode configuration have led to amplifier modules with gain above $550 \mathrm{GHz}$ [29]. With shorter gate length, results up to $670 \mathrm{GHz}$ have been demonstrated. For the latest results from $\mathrm{NGC}$, refer to the paper in this issue [46].

\section{Waveguide Packaging Using Finline Transitions}

Another interesting packaging concept for MMIC/S-MMIC/ TMIC amplifiers involves the use of finline transitions. The finline is matched to the height of the input and output waveguide, and transitioned to a suspended stripline mode where the transistors reside, all on a 2-mil-thick InP substrate. This configuration is particularly suited to differential amplifiers, and an example showing the finline transition integrated on the same substrate as a differential transistor pair is shown in Fig. 26 [47]. The differential finline amplifier module has exhibited gain up to 240 $\mathrm{GHz}$, but the method may be applied to higher frequencies.

\section{LOW NoISE AMPLIFIERS FOR THE TERAHERTZ REgIME}

\section{A. Gain and Noise Figure}

InP HEMT devices have been traditionally the device of choice for low noise amplification, mainly due to their high transconductance, high electron mobility, and high cutoff frequencies. More recently, HBTs have been developed with cutoff frequencies approaching or exceeding $1 \mathrm{THz}$, though few reports of HBT MMIC noise figures have appeared in the literature. As HBTs and associated MMIC and TMIC chips continue to improve, new results will become available. This section will focus on room temperature noise figures and gain for a variety of HEMT, mHEMT, and HBT amplifier circuits.

In Fig. 28, we show a compilation of amplifier noise figure data from various institutions and devices versus frequency, from $80-700 \mathrm{GHz}$. The solid curve is the average noise obtained from experimental results from Weinreb below $100 \mathrm{GHz}$ [48]. Data points from Teledyne, NGC, Fraunhofer, HRL, NRAO, and JPL are indicated [4], [12], [29], [44]-[46], [49]-[62]. Lowest noise figures reported for the $W$-band include those from 50-nm gate length mHEMTs from Fraunhofer [50]-[52] and 35-nm gate length HEMTs from a NGC/JPL/NRAO collaboration [55], [56], having a noise figure of 2-2.5 dB. Sb-based compound semiconductor (also known as ABCS) HEMTs, 


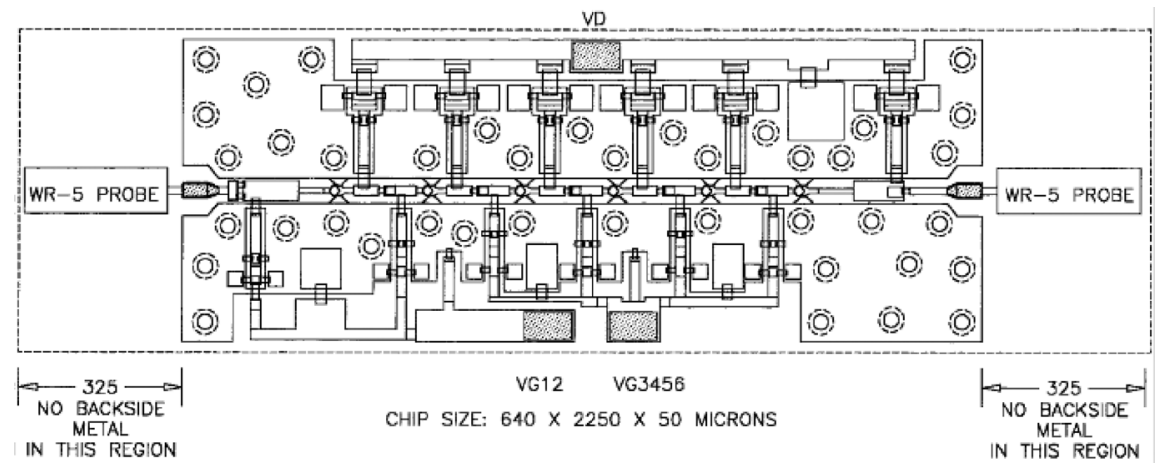

Fig. 20. First description of integrating E-plane transitions with MMICs [40].
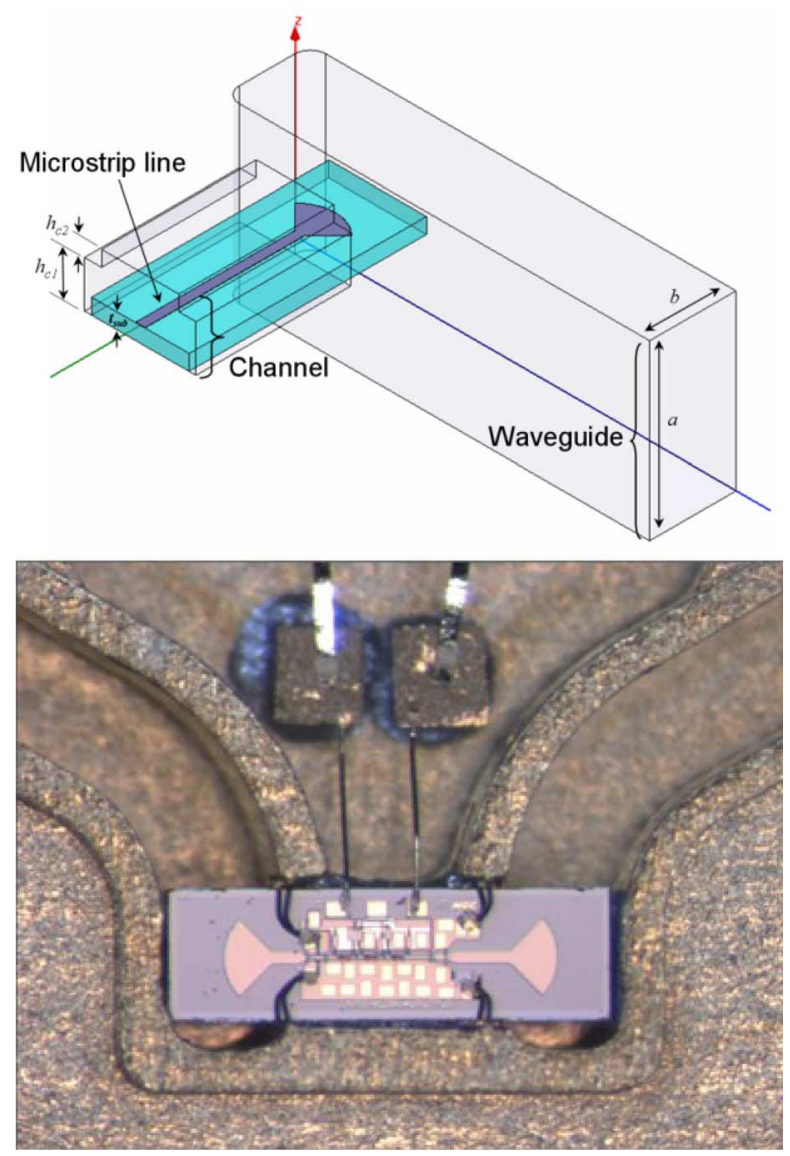

Fig. 21. Top: Radial probe with cavity. Bottom: Radial probe configuration with a 2-mil InP MMIC chip [42].

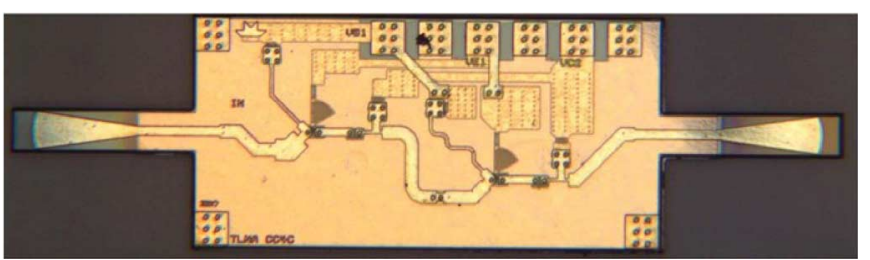

Fig. 22. HBT LNA with integrated waveguide probes, etched to remove dielectric material around the probes [12].

are indicated [57], [58], with 2.5-dB noise figures obtained at 90-94 GHz.

Results at frequencies higher than the $W$-band include those from mHEMTs with 35-, 50-, and 100-nm gate lengths [6], [7],

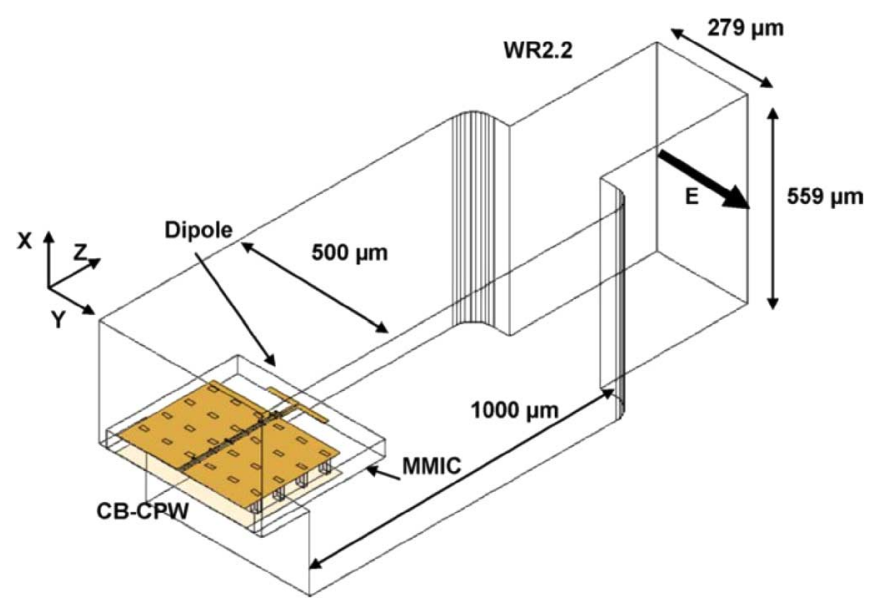

Fig. 23. Mounting configuration for conductor-backed dipole transition (after Leong [43]).

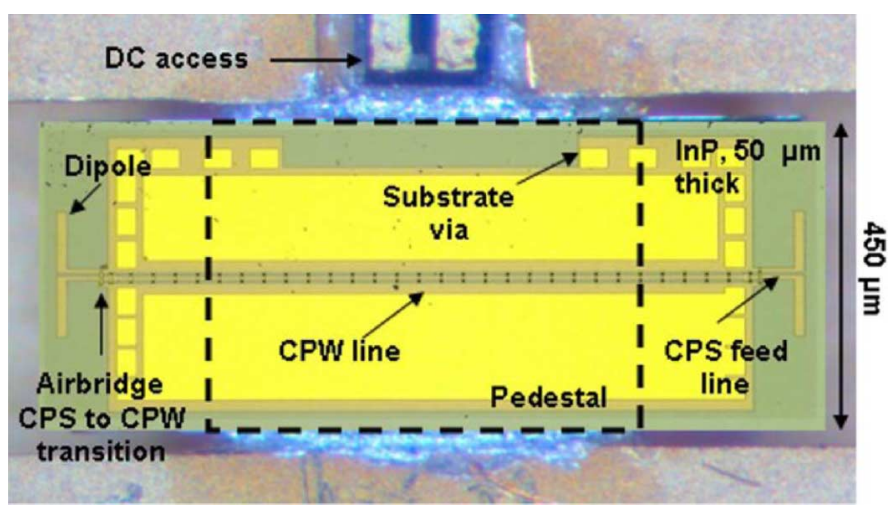

Fig. 24. Back-to-back conductor-backed dipole transitions mounted in waveguide [43].

[50]-[54]. HEMT results are found in [4], [19], [29], [44]-[46], [55], [56], and [59]-[61], having gate lengths of 30-50 nm. Exciting new results from a Teledyne InP DHBT TMIC indicate 11 $\mathrm{dB}$ noise figure at $300 \mathrm{GHz}$ - the best reported noise figure for an HBT S-MMIC to date [12]. Beyond $300 \mathrm{GHz}$, HEMT amplifiers provide the only reported noise figures to date. The highest frequencies at which noise figures have been reported are NF $\sim 11.4 \mathrm{~dB}$ at $480 \mathrm{GHz}$ [29], and $\mathrm{NF} \sim 13 \mathrm{~dB}$ at $670 \mathrm{GHz}$ [46]. With the advent of wafer probing available up to $700 \mathrm{GHz}$, new 


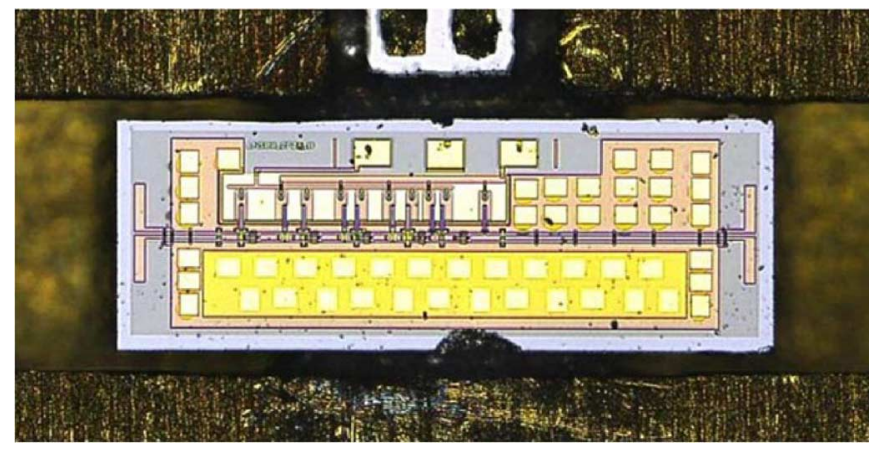

Fig. 25. 480-GHz amplifier module with integrated dipole transition [44].

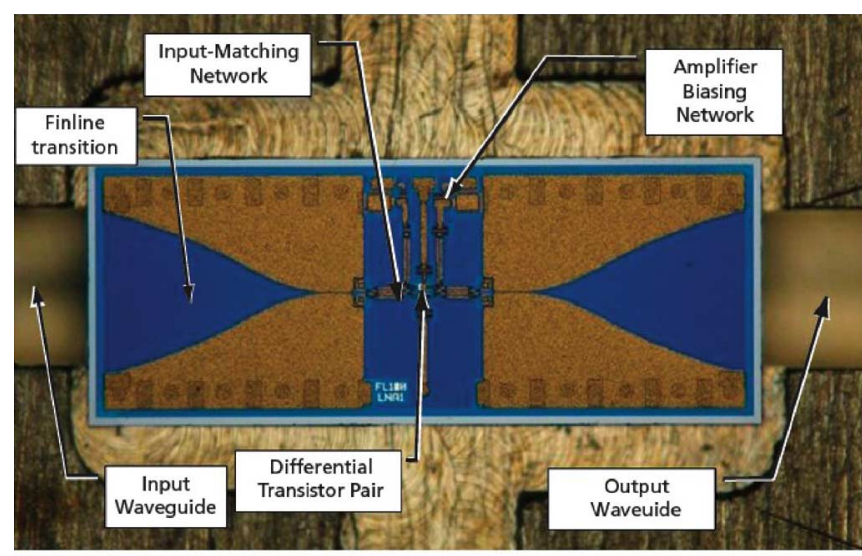

A Differential Amplifier MMIC is embedded in a waveguide package.

Fig. 26. Differential amplifier with finline transitions to waveguide, after [47].

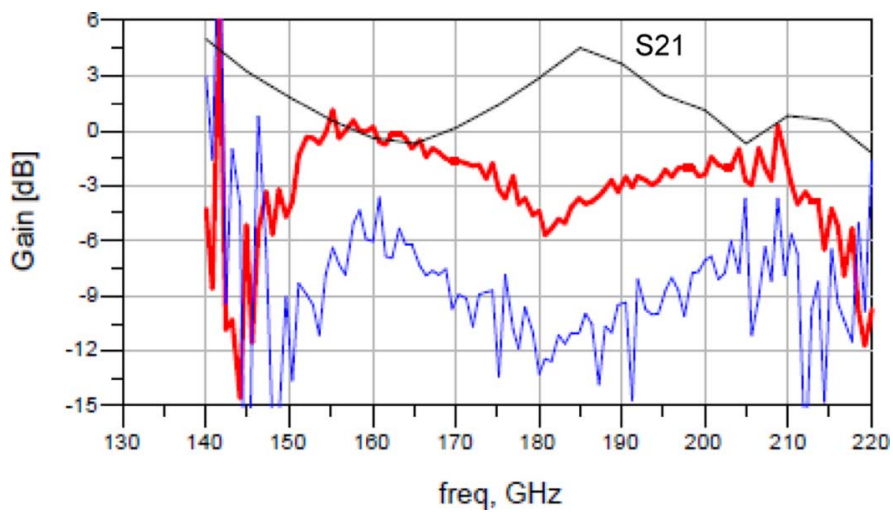

Fig. 27. Gain of differential finline amplifier module [47].

results will be added rapidly as each transistor technology matures in the coming months and years.

Much of the data for Fig. 28 were obtained in waveguide modules, however some data points were measured on-wafer. Since on-wafer data gives the most reliable comparison between device technologies, and waveguide module data includes the input loss of the waveguide and any waveguide transition, we have also tabulated the data according to which method was used for the noise measurement. A summary table of frequency, gain, noise figure (if available), measurement method (on-wafer or in module), and reference is presented in Table I, from $80 \mathrm{GHz}$ up to $700 \mathrm{GHz}$. In some cases for the

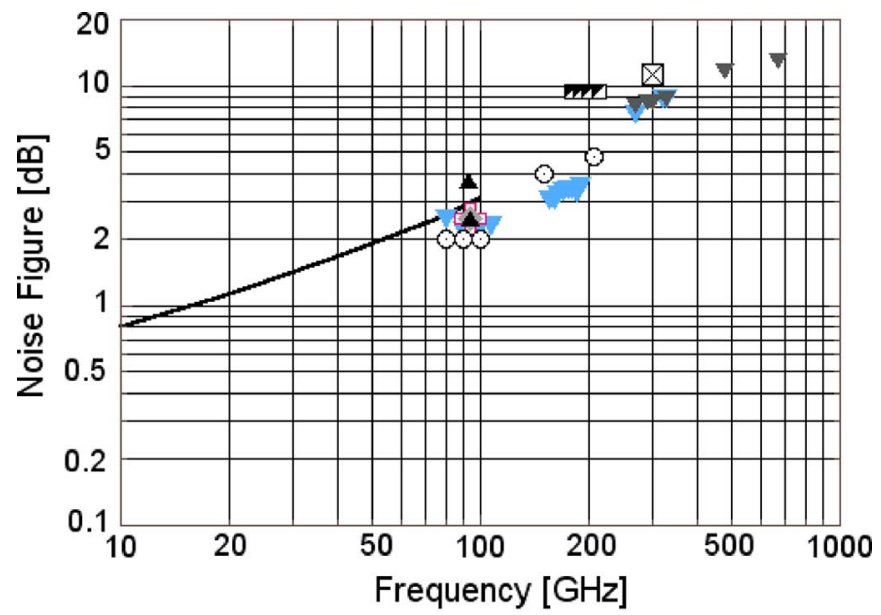

\begin{tabular}{|ll|}
\hline & S. Weinreb, Trends [48] \\
Sb-based Teledyne [57] & Sb-based, NGC [58] \\
$\nabla$ & InP $35 \mathrm{~nm}$ HEMT NGC/JPL/NRAO [19,55,56,59-61] \\
& InP $30 \mathrm{~nm}$ HEMT, NGC [29, 44-46] \\
I & InP $0.1 \mu \mathrm{m}$ HEMT, HRL [62] \\
I & InP HBT Teledyne [12] \\
$\odot$ & InP $50 \mathrm{~nm}$ mHEMT, Fraunhofer [50-53] \\
$\square$ & InP $100 \mathrm{~nm}$ mHEMT, Fraunhofer [54] \\
\hline
\end{tabular}

Fig. 28. Noise figures versus frequency for low-noise amplifier MMICs and S-MMICs using InP and ABCS technology. Black line indicates best-fit measured data below $100 \mathrm{GHz}$ prior to 2006 [48], [49].

higher frequencies, input losses can be on the order of $1-2 \mathrm{~dB}$ for the waveguide module.

Some useful consequences have emerged as a result of the high frequency S-MMIC and TMIC amplifiers-namely, the property of very low-noise figure at lower frequencies [50], [51], [55], [56]. In particular, low noise at cryogenic temperatures appears to be improved in shorter gate length HEMT MMICs compared to that for larger gate lengths $(\sim 100 \mathrm{~nm})$. In the next section, we will present a discussion of cryogenic noise data, and describe some of the first cryogenic HBT noise results.

\section{B. Cryogenic Low-Noise Amplifiers Using 35-nm HEMT Technology}

Traditionally, InP HEMTs have been well known for their low noise properties, and the decrease in noise observed when the HEMT is cooled to cryogenic temperatures. The electron mobility in the 2DEG is enhanced with decreasing temperature, as ionized impurity scattering becomes reduced, since the electrons in the HEMT channel are spatially separated from the Si delta-doped layer in the InAlAs layer. (See Fig. 1.) The transconductance $g m$ is also enhanced with decreasing temperature. Cryogenic performance in HEMTs has been well studied [63], [64], and prior MMIC amplifier noise data at $W$-band include a $30 \mathrm{~K}$ noise temperature at $90 \mathrm{GHz}$ obtained when cooling to $20 \mathrm{~K}$ ambient temperature [65].

We now present cryogenic data from the most recent 35-nm InP HEMT MMIC amplifiers fabricated at NGC. The data have been obtained with the MMICs packaged in waveguide housings, using the common Y-factor noise method similar to that described in [19]. Some of the data are obtained with a room 
TABLE I

Summary of Room Temperature LNA GaIN AND NoISE Data

\begin{tabular}{|c|c|c|c|c|c|}
\hline Freq [GHz] & Technology & Gain[dB] & NF [dB] & Measured On-Wafer or in Module & Reference \\
\hline 80 & $50 \mathrm{~nm}$ mHEMT & 22 & 2.0 & On-wafer & Leuther [50] \\
\hline 80 & $35 \mathrm{~nm}$ HEMT & 18 & 2.5 & Module & Samoska [55] \\
\hline 90 & $50 \mathrm{~nm}$ mHEMT & 20 & 2.0 & On-wafer & Leuther [50] \\
\hline 90 & $35 \mathrm{~nm}$ HEMT & 18 & 2.2 & Module & Samoska [55] \\
\hline 90 & ABCS & 5.6 & 2.5 & On-wafer & Riemer [57] \\
\hline 94 & $\mathrm{ABCS}$ & 19.4 & 2.5 & On-wafer & Mei [58] \\
\hline 94 & $0.1 \mu \mathrm{m}$ HEMT & 26 & 2.5 & On-wafer & Kurdoghlian [62] \\
\hline 100 & $50 \mathrm{~nm}$ mHEMT & 20 & 2.0 & On-wafer & Leuther [50] \\
\hline 107 & $35 \mathrm{~nm}$ HEMT & 12 & 2.3 & Module & Samoska [55] \\
\hline 150 & $50 \mathrm{~nm}$ mHEMT & 19 & 4 & On-wafer & Weissbrot [51] \\
\hline 160 & $35 \mathrm{~nm}$ HEMT & 16 & 3.0 & Module & Kangaslahti $[59,60]$ \\
\hline 190 & $35 \mathrm{~nm}$ HEMT & 16 & 3.5 & Module & Kangaslahti $[59,60]$ \\
\hline 206 & $50 \mathrm{~nm}$ mHEMT & 16 & 4.8 & On-wafer & Tessmann [52] \\
\hline 210 & $0.1 \mu \mathrm{m}$ mHEMT & 17 & 9.4 & Module & Tessmann [54] \\
\hline 255 & InP HBT & 3.5 & & On-wafer & Radisic [35] \\
\hline 270 & $35 \mathrm{~nm} \mathrm{HEMT}$ & 11.4 & 7.5 & On-wafer & Gaier [19] \\
\hline 280 & $35 \mathrm{~nm}$ mHEMT & 11.3 & & On-wafer & Griffith [6] \\
\hline 288 & InP HBT & 8.4 & $\sim 11.5$ & On-wafer & Hacker [31] \\
\hline 290 & $30 \mathrm{~nm}$ HEMT & 16 & 8.4 & Module & Deal [29] \\
\hline 300 & InP HBT & 7 & 11.2 & On-wafer & Hacker [31] \\
\hline 300 & $35 \mathrm{~nm}$ mHEMT & 13.5 & & Module & Tessmann [53] \\
\hline 300 & $30 \mathrm{~nm}$ HEMT & 17 & 8.3 & Module & Deal [29] \\
\hline 315 & InP HBT & 20.5 & & On-wafer & Urteaga [12] \\
\hline 320 & $35 \mathrm{~nm}$ HEMT & 15 & & On-wafer & Pukala [25] \\
\hline 320 & $35 \mathrm{~nm}$ mHEMT & 26 & & On-wafer & Tessmann [30] \\
\hline 324 & InP HBT & 4.8 & & On-wafer & Hacker [34] \\
\hline 325 & InP HBT & 25 & & On-wafer & Hacker [33] \\
\hline 325 & $35 \mathrm{~nm}$ HEMT & 11 & 8.7 & Module & Deal [45] \\
\hline 330 & $35 \mathrm{~nm}$ HEMT & $\sim 10$ & 8.7 & Module & Lai [61] \\
\hline 340 & $35 \mathrm{~nm}$ HEMT & 16 & & On-wafer & Deal [24] \\
\hline 350 & $35 \mathrm{~nm}$ HEMT & - & 8.9 & Module & Lai [61] \\
\hline 360 & $<50 \mathrm{~nm}$ HEMT & 11 & & Module & Lai [4] \\
\hline 390 & $<50 \mathrm{~nm}$ HEMT & 4 & & Module & Lai [4] \\
\hline 426 & $35 \mathrm{~nm}$ HEMT & 13 & & On-wafer & Samoska [26] \\
\hline 460 & $35 \mathrm{~nm}$ mHEMT & 16.1 & & On-wafer & Tessmann [7] \\
\hline 480 & $<50 \mathrm{~nm}$ HEMT & 11.4 & 11.7 & Module & Deal $[29,45]$ \\
\hline 492 & $35 \mathrm{~nm}$ HEMT & 9 & & On-wafer & Samoska [26] \\
\hline 500 & $35 \mathrm{~nm}$ mHEMT & 3.3 & N/A & On-wafer & Tessmann [7] \\
\hline 550 & $30 \mathrm{~nm}$ HEMT & 10 & N/A & Module & Deal [29] \\
\hline 670 & $30 \mathrm{~nm}$ HEMT & 8 & 13 & Module & Deal [46] \\
\hline 670 & $30 \mathrm{~nm}$ HEMT & 30 & N/A & On-wafer & Deal [46] \\
\hline
\end{tabular}

temperature $(295 \mathrm{~K})$ load and $77 \mathrm{~K}$ liquid nitrogen load, with the MMIC module in a dewar under vacuum separated from the load by a mylar window. Other data are obtained without a window, using a load which is heated to between typically $50 \mathrm{~K}$ for the hot load and $30 \mathrm{~K}$ for the cold load temperatures. Some notable highlights of the noise data include a $22 \mathrm{~K}$ noise temperature at $85 \mathrm{GHz}$ in a $W$-band MMIC amplifier [56], a wideband $<40 \mathrm{~K}$ amplifier covering $80-110 \mathrm{GHz}$ [55], and $G$-band ampli- fiers with a record noise temperature of $60 \mathrm{~K}$ at $160 \mathrm{GHz}$ [59], [60], [66].

In Fig. 29, we plot the cryogenic noise data from [55] and [56], which use HEMT MMICs with $\operatorname{In}_{0.75} \mathrm{Ga}_{0.25}$ As channels. We have observed a strong decrease in cryogenic noise temperature as a function of gate length compared to the best results from $100 \mathrm{~nm}$ gate length MMICs [65], [67]. In addition, the use of $100 \%$ InAs channels appears to decrease the amplifier 


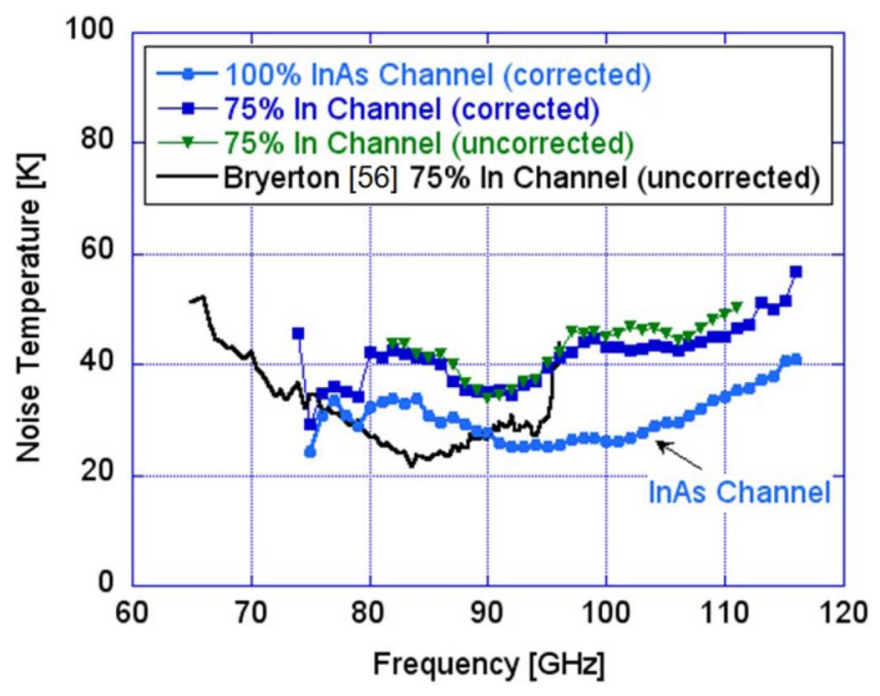

Fig. 29. $W$-band noise temperature of 35-nm gate length HEMT LNA MMIC modules, cooled to approximately $20 \mathrm{~K}$ ambient. Uncorrected data do not account for backend noise contribution, or contribution from the window in the measurement. Corrected data remove backend noise contribution [55], [56].

noise temperature as well, compared to HEMT MMICs with $\mathrm{In}_{0.75} \mathrm{Ga}_{0.25}$ As channels [55]. Work is ongoing to improve the device models (which were derived at room temperature) with cryogenic cooling. Typical model parameters which change with decreasing temperature include decreasing $C g s$ and $C g d$, as well as increasing $g m$.

In Fig. 29, we make a distinction between amplifier noise temperatures which have been corrected for backend system contributions, and those which do not include backend corrections. These corrections can be significant when the amplifier chip gain is less than $30 \mathrm{~dB}$. Both corrected and uncorrected data are shown for the same MMIC chip having $\operatorname{In}_{0.75} \mathrm{Ga}_{0.25} \mathrm{As}$ channel devices, showing that at some frequencies, the backend correction may improve the noise temperature by a few K.

For $G$-band, we have build single-amplifier MMIC modules (similar to those shown in Fig. 17) and described in detail in [59] and [60]. These were cryogenically cooled to $20 \mathrm{~K}$ and backend-corrected data are shown with open circles in Fig. 30. The lowest noise occurs in the 160-170-GHz range with a minimum noise of $60 \mathrm{~K}$. In addition to single-chip amplifier modules, we have built a superheterodyne receiver module, which includes three LNAs, a subharmonic mixer diode MMIC, and bandpass filters [66], contained in a one-cubic-inch compact waveguide module. Applications of this module include a future focal plane array instrument for a radio telescope. The module is shown in Fig. 31, with a penny for scale. The interior of the module is shown beneath in Fig. 31, with placement of the LNAs, filters and mixer relative to the waveguide inputs indicated. The measured noise from this receiver module is also shown in Fig. 30, and the noise is equal or better than that obtained from the single-amplifier module, even when not corrected for backend contribution or for possible losses due to horn and window. The noise increases near $180 \mathrm{GHz}$ due to roll-off of the bandpass filter, which was intended to block the 183-GHz $\mathrm{H}_{2} \mathrm{O}$ spectral line for astrophysical observations.

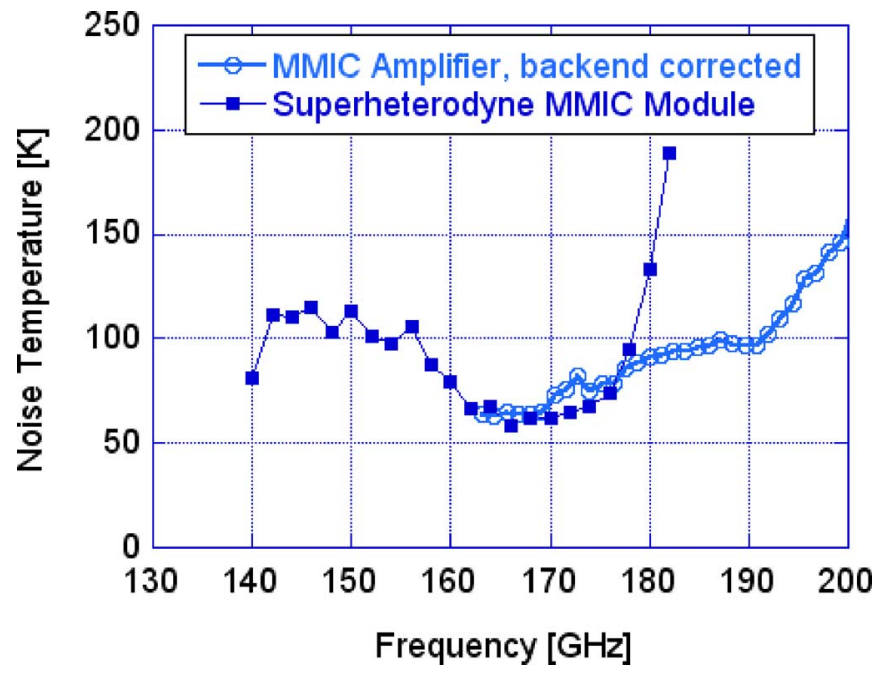

Fig. 30. $G$-band noise temperature of 35-nm gate length HEMT LNA MMIC modules, when cooled to $20 \mathrm{~K}$ ambient. Backend corrected data are for a single amplifier module. Uncorrected data are for a superheterodyne receiver module containing three LNAs, a mixer and bandpass filters. Noise increases above $180 \mathrm{GHz}$ in the superheterodyne module due to the bandpass filters.
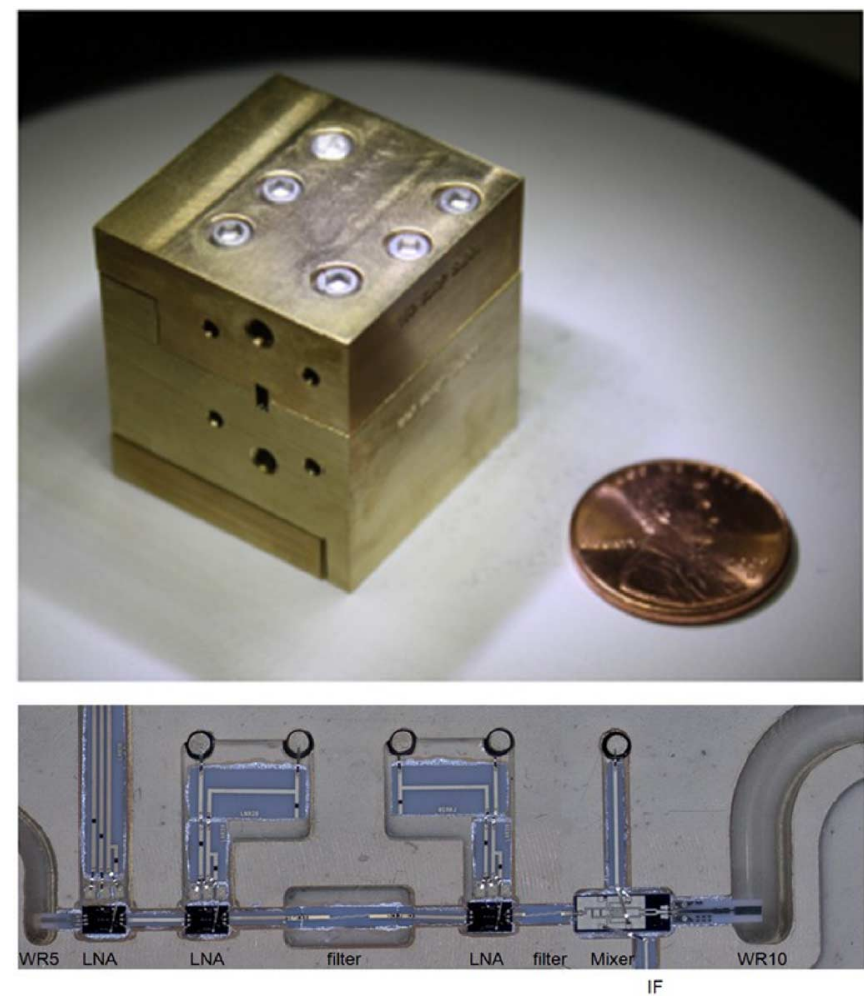

Fig. 31. Superheterodyne multichip MMIC module (top), containing in its interior (bottom) three MMIC LNAs, a bandpass filter, and subharmonic diode mixer chip.

These cryogenic results indicate that HEMT MMIC amplifiers made with TMIC transistors have unprecedented noise performance, and as gate lengths continue to decrease with further process development improvements, HEMT low noise amplifiers will likely improve with them, particularly for cryogenic applications. 

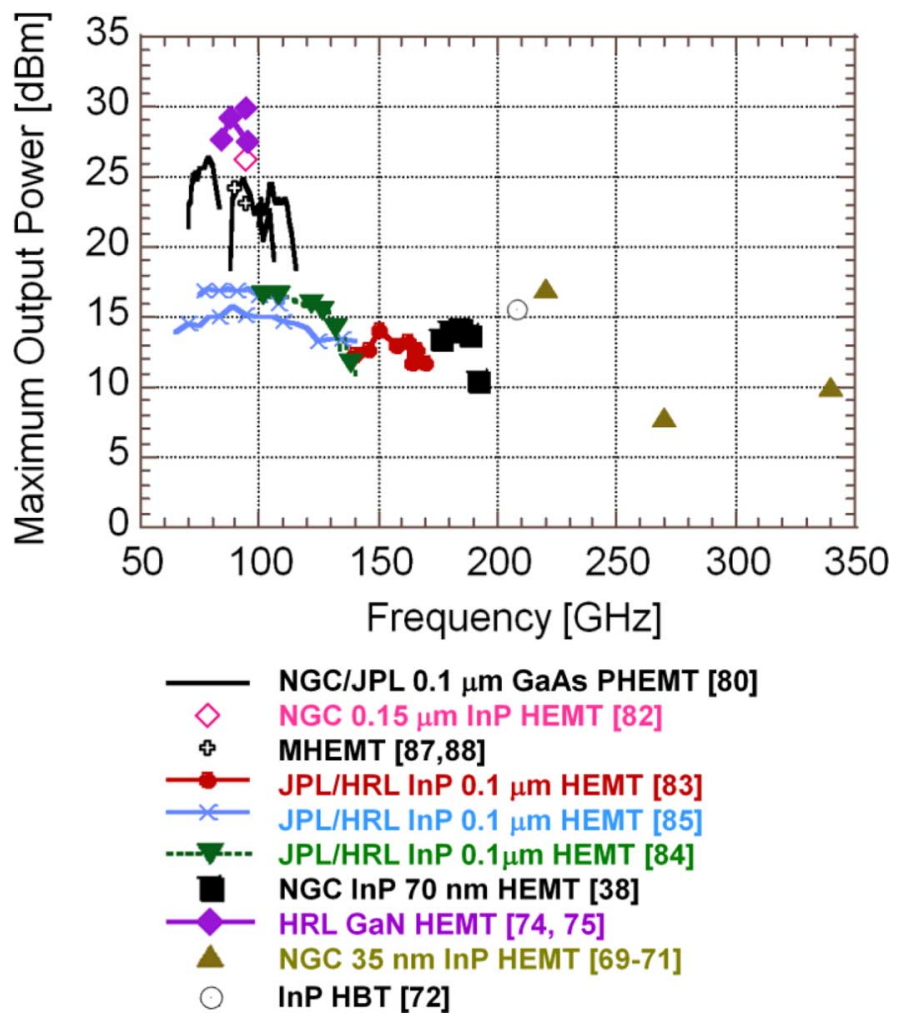

Fig. 32. State-of-the-art for MMIC power amplifiers to date: Maximum output power versus frequency for various MMIC technologies.

\section{Cryogenic HBT Low-Noise Amplifiers}

InP HBT devices have only achieved comparable $F t$ and $F \max$ values to HEMTs in recent years, and thus S-MMIC and TMIC HBT amplifiers have not been as well studied for noise properties. One HBT materials system which has been characterized for noise performance at low frequency is SiGe [68]. SiGe HBTs are being studied for their ultra-low-noise properties at low temperatures, and are interesting for a variety of applications, including IF amplification in radio astronomy heterodyne receivers, due to their comparable noise figures to InP cryogenic HEMTs at low frequencies. A model for SiGe HBT noise has been constructed and depends on the DC characteristics, including the $\beta$ of the HBT [68]. One may consider extending this analysis to InP HBTs, since their cutoff frequencies are in the $1-\mathrm{THz}$ range in the best devices. To date, no InP HBT cryogenic noise measurements have been reported, and it is hoped that in the future, the exciting new strides being made in HBT development will lead to cryogenically cooled HBT TMICs with excellent noise properties.

\section{SOLID-STATE Power AmPlifiers For the THz Regime}

In 2006, we presented a compilation of solid-state MMIC power amplifiers [49], where the maximum frequency attainable for power amplification was less than $200 \mathrm{GHz}$, and the highest power amplifier measured was $427 \mathrm{~mW}$ at $94 \mathrm{GHz}$. In recent years, some new breakthroughs in InP power amplifiers, as well as the emergence of gallium nitride ( $\mathrm{GaN})$ MMIC amplifiers for $W$-band have broken records in frequency and power. In Fig. 32, we show the best power amplifier data to date from
MMIC and S-MMIC amplifiers. In the case of InP HEMT power amplifiers, a $50-\mathrm{mW}$ power amplifier module has been designed and demonstrated at $220 \mathrm{GHz}$ - the first of its kind [69]. Results on a balanced power amplifier have produced $7.9 \mathrm{dBm}$ at $270 \mathrm{GHz}$ [70]. In addition, a data point was reported for the first S-MMIC power amplifier module, having an output power of $10 \mathrm{~mW}$ at $338 \mathrm{GHz}$ [71]. In the case of power amplifiers using InP HBTs, the highest HBT MMIC power amplifier to date has been reported above $200 \mathrm{GHz}$, with $35 \mathrm{~mW}$ at $208 \mathrm{GHz}$ [72].

GaN HEMT devices have achieved high cutoff frequencies, with recent report results of Ft $\sim 220 \mathrm{GHz}$ and Fmax $\sim$ $400 \mathrm{GHz}$ [73]. The advent of such high speed GaN transistors has led to the first GaN $W$-band MMIC power amplifiers, with $842 \mathrm{~mW}$ reported in a MMIC module at $88 \mathrm{GHz}$, from HRL Laboratories [74]. A 933-mW, 94-GHz GaN MMIC chip having an output periphery of $0.6 \mathrm{~mm}$ was reported in 2010 [75]. Additional GaN MMIC results from HRL appear in [76], and others from Fujitsu include a GaN MMIC PA with $25.4 \mathrm{dBm}$ at $76 \mathrm{GHz}$ [77].

Power-combined results for GaN MMIC amplifiers have achieved power levels as high as $3 \mathrm{~W}$ at $87 \mathrm{GHz}$ with a four-way power combiner [78], and $5 \mathrm{~W}$ at $95 \mathrm{GHz}$ [79], with a 12-way radial power combiner. GaN MMIC power amplifiers have surpassed all other solid-state device technologies in terms of power. In the future, with further device improvements, it is possible that submillimeter-wave power amplifiers will become possible with $\mathrm{GaN}$.

Additional results for MMIC and S-MMIC power amplifiers include those for GaAs PHEMTs [80], [81], InP HEMTs [38], [82]-[86], and mHEMT power amplifiers [87]-[89]. For an excellent comparison with other electronic $\mathrm{THz}$ sources, such as HEMT and HBT oscillators, Schottky diode multipliers and active two-terminal devices, see [90].

In Table II, we show the comparison between GaN HEMT, GaAs pHEMT, mHEMT, and InP HEMT, and HBT power amplifiers, as a function of frequency, and indicate the output power, power-added efficiency (PAE) (if reported), and the associated power density for each technology. Off-chip power-combined results are not included. At $W$-band, the rapidly evolving GaN HEMT MMIC power amplifiers are achieving RF power densities of more than $1 \mathrm{~W} / \mathrm{mm}$ of output gate periphery in the best devices. This is several times greater than reported in any other transistor technology, and approximately eight times the power density reported for GaAs pHEMTs. As the frequency increases, the RF power density falls off rapidly for most device technologies beyond $120 \mathrm{GHz}$. Above $200 \mathrm{GHz}$, only InP power amplifiers have been reported, with RF power densities in the $25-100-\mathrm{mW} / \mathrm{mm}$ range for HEMTs and in the $0.5-1.5 \mathrm{~mW} / \mu \mathrm{m}^{2}$ for HBTs. Power added efficiencies are similar in $W$-band between $\mathrm{GaN}$ and InP HEMT and mHEMT MMICs, in the range of $15 \%$. At higher frequencies, PAEs are in the range of a few percent.

\section{EMERGING TeCHNOLOGIES}

Some new results have been reported in SiGe HBT and CMOS technologies. SiGe transceiver chip sets using low-noise and power amplifier components have been reported up to $170 \mathrm{GHz}$ [91], [92]. A 170-GHz SiGe low-noise amplifier 
TABLE II

POWER AMPLIFIER RESULTS

\begin{tabular}{|c|c|c|c|c|c|}
\hline Freq [GHz] & Technology & Output Power & PAE \% & Power Density & Reference \\
\hline 76 & $0.12 \mu \mathrm{m}$ GaN HEMT & $347 \mathrm{~mW}$ & - & $434 \mathrm{~mW} / \mathrm{mm}$ & Masuda [77] \\
\hline 84 & $0.15 \mu \mathrm{m}$ GaN HEMT & $500 \mathrm{~mW}$ & $17 \%$ & $1670 \mathrm{~mW} / \mathrm{mm}$ & Micovic [76] \\
\hline 88 & $0.15 \mu \mathrm{m}$ GaN HEMT & $842 \mathrm{~mW}$ & $14.7 \%$ & $1400 \mathrm{~mW} / \mathrm{mm}$ & Micovic [74] \\
\hline 90 & $0.15 \mu \mathrm{m}$ mHEMT & $267 \mathrm{~mW}$ & $17 \%$ & $222 \mathrm{~mW} / \mathrm{mm}$ & Herrick [89] \\
\hline 94 & $0.1 \mu \mathrm{m}$ mHEMT & $214 \mathrm{~mW}$ & $8 \%$ & $148 \mathrm{~mW} / \mathrm{mm}$ & Tessmann [88] \\
\hline 94 & $0.15 \mu \mathrm{m}$ InP HEMT & $427 \mathrm{~mW}$ & $19 \%$ & $266 \mathrm{~mW} / \mathrm{mm}$ & Ingram [82] \\
\hline 94 & $0.15 \mu \mathrm{m}$ GaN HEMT & $933 \mathrm{~mW}$ & $13.3 \%$ & $1550 \mathrm{~mW} / \mathrm{mm}$ & Micovic [75] \\
\hline 95 & $0.15 \mu \mathrm{m}$ GaN HEMT & $560 \mathrm{~mW}$ & - & $930 \mathrm{~mW} / \mathrm{mm}$ & Micovic [74] \\
\hline $75-110$ & $0.1 \mu \mathrm{m}$ GaAs pHEMT & $200 \mathrm{~mW}$ & $4-9 \%$ & $160 \mathrm{~mW} / \mathrm{mm}$ & Wang [80] \\
\hline $75-110$ & $0.1 \mu \mathrm{m}$ InP HEMT & $40 \mathrm{~mW}$ & $6 \%$ & $133 \mathrm{~mW} / \mathrm{mm}$ & Samoska [85] \\
\hline 115 & $70 \mathrm{~nm}$ GaAs pHEMT & $25 \mathrm{~mW}$ & - & $200 \mathrm{~mW} / \mathrm{mm}$ & Morgan [81] \\
\hline 120 & $0.1 \mu \mathrm{m}$ InP HEMT & $29 \mathrm{~mW}$ & $4 \%$ & $96 \mathrm{~mW} / \mathrm{mm}$ & Samoska [84] \\
\hline 150 & $0.1 \mu \mathrm{m}$ InP HEMT & $20 \mathrm{~mW}$ & $3 \%$ & $66 \mathrm{~mW} / \mathrm{mm}$ & Samoska [83] \\
\hline 190 & $70 \mathrm{~nm}$ InP HEMT & $20 \mathrm{~mW}$ & $9.5 \%$ & $166 \mathrm{~mW} / \mathrm{mm}$ & Huang [38] \\
\hline 192 & $0.1 \mu \mathrm{m}$ mHEMT & $8.9 \mathrm{~mW}$ & $4 \%$ & $55 \mathrm{~mW} / \mathrm{mm}$ & Kallfass [87] \\
\hline 208 & InP HBT & $35.6 \mathrm{~mW}$ & - & $1.5 \mathrm{~mW} / \mu \mathrm{m}^{2} *$ & Reed [72] \\
\hline 217.5 & $<50 \mathrm{~nm}$ InP HEMT & $51 \mathrm{~mW}$ & $2.3 \%$ & $63 \mathrm{~mW} / \mathrm{mm}$ & Radisic [69] \\
\hline 270 & $<50 \mathrm{~nm}$ InP HEMT & $6.1 \mathrm{~mW}$ & $5.2 \%$ & $50 \mathrm{~mW} / \mathrm{mm}$ & Deal [70] \\
\hline 324 & InP HBT & $1.3 \mathrm{~mW}$ & $0.6 \%$ & $\sim 0.5 \mathrm{~mW} / \mu \mathrm{m}^{2} *$ & Hacker [34] \\
\hline 330 & $<50 \mathrm{~nm}$ InP HEMT & $2 \mathrm{~mW}$ & - & $25 \mathrm{~mW} / \mathrm{mm}$ & Deal [86] \\
\hline 338 & $<50$ InP HEMT & $10 \mathrm{~mW}$ & - & $62 \mathrm{~mW} / \mathrm{mm}$ & Radisic [71] \\
\hline
\end{tabular}

having up to $25 \mathrm{~dB}$ of gain was developed in 2010 [91]. Low-noise amplifiers in the $140-150-\mathrm{GHz}$ range fabricated in 65-nm CMOS have been reported [91], [93], [94]. Other examples of SiGe circuits operating over $100 \mathrm{GHz}$ exist in the literature [95], [96]. SiGe transistors are known to have high cutoff frequencies with cryogenic cooling, and one interesting paper reported measuring a SiGe HBT with $F \max \sim 615 \mathrm{GHz}$ obtained at $\mathrm{T}=4.5 \mathrm{~K}$ [97]. It is projected that with proper device scaling, room temperature SiGe HBT cutoff frequencies could approach $1 \mathrm{THz}$ [97].

\section{CONCLUSION}

In this work, we have presented the leading technologies for achieving $1 \mathrm{THz}$ amplifiers with solid-state devices, and discussed the devices, circuits, and packaging required for TMIC amplifiers. InP HEMTs, mHEMTs, and HBTs have achieved the highest frequency gain reported to date, with the best measured results reported for InP short gate length HEMTs. For power, GaN HEMTs have achieved the highest power at lower frequencies (more than $0.5 \mathrm{~W}$ at $\sim 100 \mathrm{GHz}$ ), while at higher frequencies, InP HEMTs and HBTs have the highest reported power, in the $30-50 \mathrm{~mW}$ range around $200 \mathrm{GHz}$ and in the $1-10-\mathrm{mW}$ range for amplifiers around $300 \mathrm{GHz}$. The majority of the technologies described in this paper have been demonstrated only in the past one to two years, and for practical use, the reliability of the technologies will need to studied and compared, particularly as the relevant feature size (emitter width or gate length) will need to shrink further for $1-\mathrm{THz}$ operation. Applications for solid-state amplifiers in the terahertz regime include radio astronomy, remote sensing, earth science, radar, imaging and hidden weapons detection. The advent of TMIC amplifiers will enable gain and sensitivities which have never before been possible with active three terminal devices.

\section{ACKNOWLEDGMENT}

The author would like to thank numerous colleagues for helpful discussions, providing of material and data for this work and for their excellent contributions to the field. These include C. Bolognesi, E. Bryerton, G. Chattopadhyay, S. Church, K. Cleary, D. Dawson, W. Deal, H. Eisele, A. Fung, T. Gaier, Z. Griffith, J. Hacker, V. Jain, P. Kangaslahti, R. Lai, C. Lawrence, I. Mehdi, K. Leong, Y. C. Leong, G. Mei, M. Micovic, M. Morgan, H. Owen, A. Peralta, D. Pukala, G. Rebeiz, V. Radisic, R. Reeves, M. Rodwell, S. Sarkozy, P. Siegel, M. Sieth, M. Soria, A. Tessmann, S. Weinreb, M. Urteaga, M. Varonen, S. Voinigescu, and P. Voll.

\section{REFERENCES}

[1] P. Siegel, "Terahertz technology," IEEE Trans. Microw. Theory Tech., vol. 50, no. 3, pp. 910-928, Mar. 2002.

[2] J. Booske, G. Park, R. Dobbs, C. Kory, G. Neil, C. Joye, J. Park, and R. Temkin, "Vacuum electronic sources of high power coherent terahertz radiation," IEEE Trans. Terahertz Sci. Technol., vol. 1, no. 1, Sep. 2011.

[3] A. R. Alt and C. R. Bolognesi, Personal communication [Online]. Available: http://www.mwe.ee.ethz.ch/

[4] R. Lai, X. B. Mei, S. Sarkozy, W. Yoshida, P. H. Liu, J. Lee, M. Lange, V. Radisic, K. Leong, and W. Deal, "Sub $50 \mathrm{~nm} \mathrm{InP} \mathrm{HEMT} \mathrm{with} \mathrm{f}_{\mathrm{T}}=$ $586 \mathrm{GHz}$ and amplifier circuit gain at $390 \mathrm{GHz}$ for sub-millimeter wave applications," in Proc. InP Related Mater. Conf., Kagawa, Jul. 2010, pp. 1-3. 
[5] G. I. Ng, K. Radhakrishan, and H. Wang, "Are we there yet?-A metamorphic HEMT and HBT perspective," in Proc. 13th GaAs Symp., Paris, France, 2005, pp. 13-19.

[6] Z. Griffith, W. Ha, P. Chen, D. H. Kim, and B. Brar, “A 206-294 GHz 3 stage amplifier in $35 \mathrm{~nm}$ InP mHEMT using a thin-film microstrip environment," in 2010 IEEE MTT-S Int. Microw. Symp. Dig., Anaheim, CA, Jun. 2010, pp. 57-60.

[7] A. Tessmann, A. Leuther, R. Loesch, M. Seelmann-Eggebert, and H. Massler, "A metamorphic HEMT S-MMIC amplifier with $16.1 \mathrm{~dB}$ Gain at $460 \mathrm{GHz}$," in IEEE Compound Semicond. IC Symp., Monterey, CA, Oct. 2010, pp. 1-4.

[8] S. M. Sze, High Speed Semiconductor Devices. New York: Wiley, 1990.

[9] M. Rodwell, M. Le, and B. Brar, "InP bipolar ICs: Scaling roadmaps, frequency limits, manufacturable technologies," Proc. IEEE, Special Issue on A Future of Integrated Electronics: Moving Beyond Moore's Law and Off the Roadmap, vol. 96, no. 2, pp. 271-286, Feb. 2008.

[10] M. Rodwell, E. Lobisser, M. Wistey, V. Jain, A. Baraskar, E. Lind, J. Koo, Z. Griffith, J. Hacker, M. Urteaga, D. Mensa, R. Pierson, and B. Brar, "THz bipolar transistor circuits: Technical feasibility, technology development, integrated circuit results," in Proc. IEEE Compound Semicond. IC Symp., Monterey, CA, Oct. 2008, pp. 1-3.

[11] V. Jain, J. C. Rode, H.-W. Chiang, A. Baraskar, E. Lobisser, B. J. Thibeault, M. Rodwell, M. Urteaga, D. Loubychev, A. Snyder, Y. Wu, J. M. Fastenau, and W. K. Liu, "1.0 THz fmax InP DHBTs in a refractory emitter and self-aligned base process for reduced base access resistance," in Proc. Device Res. Conf., Santa Barbara, CA, Jun. 2011, pp. $271-272$.

[12] M. Urteaga, M. Seo, J. Hacker, Z. Griffith, A. Young, R. Pierson, P. Rowell, A. Skalare, and M. J. W. Rodwell, "InP HBT integrated circuit technology for terahertz frequencies," in Proc. IEEE Compound Semicond. IC Symp., Oct. 2010, pp. 1-4.

[13] OML [Online]. Available: http://omlinc.com/

[14] A. Fung, D. Dawson, L. Samoska, K. Lee, T. Gaier, P. Kangaslahti, C. Oleson, A. Denning, Y. Lau, and G. Boll, "Two port vector network analyzer measurements in the $218-344$ and $356-500 \mathrm{GHz}$ frequency bands," IEEE Trans Microw. Theory Tech., vol. 54, no. 12, pt. 2, pp. 4507-4512, Dec. 2006.

[15] A. Fung, L. Samoska, G. Chattopadhyay, T. Gaier, P. Kangaslahti, D. Pukala, C. Oleson, A. Denning, and Y. Lau, "Two-port vector network analyzer measurements up to $508 \mathrm{GHz}$," IEEE Trans. Instrum. Meas., vol. 57, no. 6, pp. 1166-1170, Jun. 2008.

[16] GGB [Online]. Available: http://ggb.com/

[17] A. K. Fung, D. Dawson, L. Samoska, K. Lee, C. Oleson, and G. Boll, "On-wafer vector network analyzer measurements in the $220-325 \mathrm{GHz}$ frequency band," in 2006 IEEE MTT-S Int. Microw. Symp. Dig., San Francisco, CA, Jun. 2006, pp. 1931-1934.

[18] K. M. Fung, L. A. Samoska, D. M. Pukala, D. E. Dawson, P. P. Kangaslahti, T. C. Gaier, C. Lawrence, G. Boll, R. Lai, and X. Mei, "Onwafer S-parameter measurements in the 325-508 GHz band," Defense Tech. Briefs, May 2011 [Online]. Available: http://www.defensetechbriefs.com/component/content/article/9868

[19] T. Gaier, L. Samoska, A. Fung, W. R. Deal, V. Radisic, X. B. Mei, W. Yoshida, P. H. Liu, J. Uyeda, M. Barsky, and R. Lai, "Measurement of a $270 \mathrm{GHz}$ low noise amplifier with $7.5 \mathrm{~dB}$ noise figure," IEEE Microw. Wireless Compon. Lett., vol. 17, no. 7, pp. 546-548, Jul. 2007.

[20] Cascade Microtech [Online]. Available: http://www.cmicro.com/

[21] Virginia Diodes Website [Online]. Available: http://vadiodes.com/

[22] L. Chen, C. Zhang, T. J. Reck, C. Groppil, A. Arsenovic, A. Lichtenberger, R. M. Weikle, and N. S. Barker, "Terahertz micromachined on-wafer probes: Repeatability and robustness," presented at the 2011 IEEE MTT-S Int. Microw. Symp., Baltimore, MD, Jun. 2011.

[23] D. Dawson, L. Samoska, A. K. Fung, K. Lee, R. Lai, R. Grundbacher, P. H. Lin, and R. Raja, "Beyond G-Band: A $235 \mathrm{GHz}$ InP MMIC amplifier," IEEE Microw. Wireless Compon. Lett., vol. 15, no. 2, pp. 874-876, Dec. 2005.

[24] W. R. Deal, X. B. Mei, V. Radisic, W. Yoshida, P. H. Liu, J. Uyeda, M. Barsky, T. Gaier, A. Fung, and R. Lai, "Demonstration of a S-MMIC LNA with 16-dB gain at $340 \mathrm{GHz}$," in Proc. IEEE Compound Semicond. IC Symp., Portland, OR, Oct. 2007, pp. 1-4.

[25] D. Pukala, L. Samoska, T. Gaier, A. Fung, X. B. Mei, W. Yoshida, J. Lee, J. Uyeda, P. Liu, W. R. Deal, V. Radisic, and R. Lai, "Submillimeter-wave InP MMIC amplifiers from 300-345 GHz," IEEE Microw. Wireless Compon. Lett., pp. 61-63, Jan. 2008.
[26] L. Samoska, A. Fung, D. Pukala, P. Kangaslahti, R. Lai, S. Sarkozy, X. B. Mei, and G. Boll, "On-wafer measurements of S-MMIC amplifiers from 400-500 GHz," presented at the 2011 IEEE MTT-S Int. Microw. Symp., Baltimore, MD, Jun. 2011.

[27] W. R. Deal, L. Yujiri, M. Siddiqui, and R. Lai, "Advanced MMIC for passive millimeter and submillimeter wave imaging," in Proc. 2007 IEEE Int. Solid-State Circuits Conf., pp. 572-622.

[28] A. Tessmann, " $220 \mathrm{GHz}$ metamorphic HEMT amplifier MMICs for high-resolution imaging applications," IEEE J. Solid-State Circuits, vol. 40, no. 10, pp. 2070-2076, Oct. 2005.

[29] W. R. Deal, K. Leong, X. B. Mei, S. Sarkozy, V. Radisic, J. Lee, P. H. Liu, W. Yoshida, J. Zhou, and M. Lange, "Scaling of InP HEMT cascode integrated circuits to $\mathrm{THz}$ frequencies," in Proc. IEEE Compound Semicond. IC Symp., Oct. 2010, pp. 1-4.

[30] A. Tessmann, A. Leuther, H. Massler, V. Hur, M. Kuri, M. Zink, M. Riessle, and R. Losch, "High gain submillimeter-wave mHEMT amplifier MMICs," in 2010 IEEE MTT-S Int. Microw. Symp. Dig., Anaheim, CA, Jun. 2010, pp. 53-56.

[31] J. Hacker, M. Seo, A. Young, Z. Griffith, M. Urteaga, T. Reed, and M. Rodwell, "THz MMICs based on InP HBT technology," in 2010 IEEE MTT-S Int. Microw. Symp. Dig., Anaheim, CA, Jun. 2010, pp. $1126-1129$

[32] H. J. Park, J. S. Rieh, M. Kim, and J. Hacker, "300 GHz six-stage differential-mode amplifier," in 2010 IEEE MTT-S Int. Microw. Symp. Dig., Anaheim, CA, Jun. 2010, pp. 49-52.

[33] J. B. Hacker, Y. M. Lee, H. J. Park, J. S. Rich, and M. Kim, “A 325 $\mathrm{GHz}$ InP HBT differential-mode amplifier," IEEE Microw. Wireless Compon. Lett., vol. 21, no. 5, pp. 264-266, May 2011.

[34] J. Hacker, M. Urteaga, D. Mensam, R. Pierson, M. Jones, Z. Griffith, and M. Rodwell, "250 nm InP DHBT monolithic amplifiers with 4.8 dB gain at $324 \mathrm{GHz}$," in 2008 IEEE MTT-S Int. Microw. Symp. Dig., Jun. 2008, pp. 403-406.

[35] V. Radisic, D. Sawdai, D. Scott, W. R. Deal, L. Dang, D. Li, A. Cavus, A. Fung, L. Samoska, R. To, T. Gaier, and R. Lai, "Demonstration of 184 and 255-GHz amplifiers using InP HBT technology," IEEE Microw. Wireless Compon. Lett., vol. 18, no. 4, pp. 281-283, Apr. 2008.

[36] Y.C. Leong and S. Weinreb, "Full band waveguide-to-microstrip probe transitions," in IEEE MTT-S Int. Microwave Symp. Dig., Jun. 1999, pp. $1435-1438$

[37] L. Samoska, S. Weinreb, and A. Peralta, "A waveguide power amplifier module for 80-150 GHz," NASA Tech Briefs May 2006 [Online]. Available: http://www.techbriefs.com/component/content/article/1536

[38] P. P. Huang, R. Lai, R. Grundbacher, and B. Gorospe, "A $20 \mathrm{~mW}$ G-band monolithic driver amplifier using $0.07 \mu \mathrm{m} \mathrm{InP} \mathrm{HEMT,"} \mathrm{in}$ IEEE MTT-S Int. Microwave Symp. Dig., Jun. 2006, pp. 806-809.

[39] A. Tessmann, A. Leuther, V. Hurm, H. Massler, M. Zink, M. Kuri, M. Riessle, R. Losch, M. Schlechtweg, and O. Ambacher, "A $300 \mathrm{GHz}$ mHEMT amplifier module," in Proc. InP Related Mater. Conf., Newport Beach, CA, May 2009, pp. 196-199.

[40] S. Weinreb, T. Gaier, R. Lai, M. Barsky, Y. C. Leong, and L. Samoska, "High gain 150-215 GHz MMIC amplifier with integral waveguide transitions," IEEE Microw. Guided Wave Lett., vol. 9, no. 7, pp. 282-284, Jul. 1999.

[41] J. W. Kooi, G. Chattopadhyay, S. Withington, F. Rice, J. Zmuidzinas, C. Walker, and G. Yassin, "A full-height waveguide-to-thin-film microstrip transition with exceptional RF bandwidth and coupling efficiency," Int. J. IR MM Waves, vol. 24, no. 3, pp. 261-284, 2003.

[42] L. Samoska, W. R. Deal, G. Chattopadhyay, D. Pukala, A. Fung, T. Gaier, M. Soria, V. Radisic, X. Mei, and R. Lai, "A submillimeterwave HEMT amplifier module with integrated waveguide transitions operating above $300 \mathrm{GHz}$," IEEE Trans. Microw. Theory Tech., vol. 56, no. 6, pp. 1380-1388, Jun. 2008.

[43] K. Leong, W. R. Deal, V. Radisic, X. B. Mei, J. Uyeda, L. Samoska, A Fung, T. Gaier, and R. Lai, "A $340 \mathrm{GHz}$ integrated CBCPW- to-waveguide transition for sub millimeter-wave MMIC packaging," IEEE Microw. Wireless Compon. Lett., vol. 19, no. 6, pp. 413-415, Jun. 2009.

[44] W. R. Deal, X. B. Mei, V. Radisic, K. Leong, S. Sarkozy, B. Gorospe, J. Lee, P. H. Liu, W. Yoshida, J. Zhou, M. Lange, J. Uyeda, and R. Lai, "Demonstration of a $0.48 \mathrm{THz}$ amplifier module using InP HEMT transistors," IEEE Microw. Wireless Compon. Lett., vol. 20, no. 5, pp. 289-291, May 2010.

[45] W. R. Deal, "Solid-state amplifiers for terahertz electronics," in 2010 IEEE MTT-S Int. Microw. Symp. Dig., Anaheim, CA, Jun. 2010, pp. $1122-1125$. 
[46] W. R. Deal, X. B. Mei, K. Leong, V. Radisic, S. Sarkozy, B. Gorospe, J. Lee, P. H. Liu, W. Yoshida, J. Zhou, M. Lange, and R. Lai, “Terahertz monolithic integrated circuits using InP high electron mobility transistors," IEEE Trans. Terahertz Sci. Technol., vol. 1, no. 1, Sep. 2011.

[47] P. Kangaslahti, E. Schlecht, and L. Samoska, "Differential InP HEMT MMIC amplifiers embedded in waveguides," in NASA Tech Briefs, Aug. 2009.

[48] S. Weinreb, California Inst. of Technol. Pasadena, CA, private communication, 2003.

[49] L. Samoska, "Towards terahertz MMIC amplifiers: Present status and trends," in 2006 IEEE MTT-S Int. Microw. Symp. Dig., Jun. 2006, pp. 333-336.

[50] A. Leuther, A. Tessmann, I. Kalfass, R. Losch, M. Seelmann-Eggebert, N. Wadefalk, F. Schafer, J. D. Gallego-Puyol, M. Schlechtweg, M. Mikulla, and O. Ambacher, "Metamorphic HEMT technology for lownoise applications," in Proc. InP Rel. Mater. Conf., Newport Beach, CA, May 2009, pp. 188-191.

[51] E. Weissbrodt, I. Kallfass, R. Weber, A. Tessmann, H. Massler, and A. Leuther, "Low-noise amplifiers in D-band using $100 \mathrm{~nm}$ and 50 nm mHEMT technology," in Proc. German Microw. Conf., 2010, pp. $55-58$.

[52] A. Tessmann, I. Kalfass, A. Leuther, H. Massler, M. Kuri, M. Riessle, M. Zink, R. Sommer, A. Wahlen, H. Essen, V. Hurm, M. Schlechtweg, and O. Ambacher, "Metamorphic HEMT MMICs and modules for use in a high-bandwidth $210 \mathrm{GHz}$ radar," IEEE J. Solid State Circuits, vol. 43, no. 10, pp. 2194-2205, Oct. 2008.

[53] A. Tessmann, A. Leuther, H. Massler, M. Kuri, and R. Loesch, "A metamorphic 220-320 GHz HEMT amplifier MMIC," in Proc. IEEE Comp. Semicond. IC Symp., Oct. 2008, pp. 1-4.

[54] A. Tessmann, A. Leuther, M. Kuri, H. Massler, M. Riessle, H. Essen, S. Stanko, R. Sommer, M. Zink, R. Stibal, W. Reinert, and M. Schlechtweg, "220 GHz low-noise amplifier modules for radiometeric imaging applications," in Proc. 1st Eur. Microw. Integrated Circuits Conf., Manchester, U.K., Sep. 2006, pp. 137-140.

[55] L. Samoska, S. Church, K. Cleary, A. K. Fung, T. Gaier, P. Kangaslahti, R. Lai, J. Lau, X. B. Mei, M. M. Sieth, R. Reeves, and P. Voll, "Cryogenic MMIC low noise amplifiers for W-band and beyond," in Proc. 22nd Int. Symp. Space Terahertz Technol., Tucson, AZ, Apr. 2011.

[56] E. W. Bryerton, X. B. Mei, Y. M. Kim, W. Deal, W. Yoshida, M. Lange, J. Uyeda, M. Morgan, and R. Lai, "A W-band low noise amplifier with 22 K noise temperature," in 2009 IEEE MTT-S Int. Microw. Symp. Dig., Charlottesville, VA, Jun. 2009, pp. 681-684.

[57] P. J. Riemer, B. R. Buhrow, J. B. Hacker, J. Bergman, B. Brar, B. K. Gilbert, and E. S. Daniel, "Low-power W-band CPWG InAs/AlSb HEMT low-noise amplifier," IEEE Microw. Wireless Compon. Lett., vol. 16, no. 1, pp. 40-42, Jan. 2006.

[58] X. B. Mei, C. H. Lin, L. J. Lee, Y. M. Kim, P. H. Lie, M. Lange, A. Cavus, R. To, M. Nishimoto, and R. Lai, "A W-band InGaAs/InAlAs/InP HEMT low-noise amplifier MMIC with $2.5 \mathrm{~dB}$ noise figure and $19.4 \mathrm{~dB}$ gain at $94 \mathrm{GHz}$," in Proc. Indium Phosphide Rel. Mater. Conf., May 2008, pp. 1-3.

[59] P. Kangaslahti, D. Pukala, T. Gaier, W. Deal, X. Mei, and R. Lai, "Low noise amplifier for $180 \mathrm{GHz}$ frequency band," in 2008 IEEE MTT-S Int. Microwave Symp. Dig., Charlottesville, VA, Jun. 2008, pp. 681-684.

[60] P. Kangaslahti, "Recent developments in $180 \mathrm{GHz}$ MMIC LNA and receiver technology," in Proc. 11th Specialist Meeting on Microw. Radiometry Remote Sens. Environment (MicroRad), Mar. 2010, pp. 272-275.

[61] R. Lai, W. R. Deal, V. Radisic, K. Leong, X. B. Mei, S. Sarkozy, T. Gaier, L. Samoska, and A. Fung, "Sub-MMW active integrated circuits based on $35 \mathrm{~nm}$ InP HEMT technology," in Proc. InP Rel. Mater. Conf., Newport Beach, CA, May 2009, pp. 185-187.

[62] A. Kurdoghlian, H. P. Moyer, M. Wetzel, and A. Schmitz, HRL Laboratories, LLC, private communication, 2005.

[63] K. H. George Duh, M. Pospieszalski, W. F. Kopp, P. Ho, A. A. Jabra, P.-C. Chao, P. M. Smith, L. F. Lester, J. M. Ballingall, and S. Weinreb, "Ultra-low-noise cryogenic high-electron mobility transistors," IEEE Trans. Electron Devices, vol. 35, no. 3, pp. 249-256, 1988.

[64] M. W. Pospieszalski, "Modeling of noise parameters of MESFETs and MODFETs and their frequency and temperature dependence," IEEE Trans. Microw. Theory Tech., vol. 7, no. 9, pp. 1340-1350, Sep. 1989.

[65] S. Weinreb, R. Lai, N. Erickson, T. Gaier, and J. Wielgus, "W-band InP wideband MMIC LNA with $30 \mathrm{~K}$ noise temperature," in IEEE MTT-S Int. Microw. Symp. Dig., Jun. 1999, pp. 101-104.
[66] P. Voll, L. Samoska, S. Church, J. Lau, M. Sieth, T. Gaier, P. Kangaslahti, M. Soria, S. Tantawi, and D. Van Winkle, "A G-band cryogenic MMIC heterodyne receiver module for astrophysical applications," in Proc. Eur. Microw. Conf., Manchester, U.K., Sep. 2011, accepted for publication.

[67] R. Raja, M. Nishimoto, B. Osgood, M. Barsky, M. Sholley, R. Quon, G. Barber, P. Liu, R. Lai, F. Hinte, G. Haviland, and B. Vacek, "A $183 \mathrm{GHz}$ low noise amplifier module with $5.5 \mathrm{~dB}$ noise figure for the conicalscanning microwave imager sounder (CMIS) program," in 2001 IEEE MTT-S Int. Microw. Symp. Dig., May 2001, vol. 3, pp. 1955-1958.

[68] S. Weinreb, J. C. Bardin, and H. Mani, "Design of cryogenic Sige low noise amplifiers," IEEE Trans. Microw. Theory Tech., vol. 55, no. 11, pp. 2306-2312, Nov. 2007.

[69] V. Radisic, K. M. K. H. Leong, X. Mei, S. Sarkozy, W. Yoshida, P.-H. Liu, J. Uyeda, R. Lai, and W. R. Deal, "A $50 \mathrm{~mW} 220 \mathrm{GHz}$ power amplifier module," in 2010 IEEE MTT-S Int. Microw. Symp. Dig., Anaheim, CA, Jun. 2010, pp. 45-48.

[70] W. R. Deal, X. B. Mei, V. Radisic, Bayuk, A. Fung, W. Yoshida, P. H. Liu, J. Uyeda, L. Samoska, T. Gaier, and R. Lai, "A balanced submillimeter wave power amplifier," in 2008 IEEE MTT-S Int. Microw. Symp. Dig., Jun. 2008, pp. 399-402.

[71] V. Radisic, W. R. Deal, K. M. K. H. Leong, W. Yoshida, P. H. Liu, J. Uyeda, A. Fung, L. Samoska, T. Gaier, and R. Lai, "A $10 \mathrm{~mW}$ submillimeter wave solid state power amplifier module," IEEE Trans. Microw. Theory Tech., vol. 58, no. 7, pp. 1903-1909, Dec. 2010.

[72] T. B. Reed, M. J. W. Rodwell, Z. Griffith, P. Rowell, M. Urteaga, M. Field, and J. Hacker, " $35 \mathrm{~mW}$ multi-cell InP HBT amplifiers with on-wafer power combing for $220 \mathrm{GHz}$ applications," in Proc. IEEE Compound Semicond. IC Symp., 2011, submitted for publication.

[73] K. Shinohara, A. Corrion, D. Regan, I. Milosavljevic, D. Brown, S. Burnham, P. J. Willladsen, C. Butler, A. Schmitz, D. Wheeler, A. Fung, and M. Micovic, "220 GHz ft and $400 \mathrm{GHz}$ fmax in $40 \mathrm{~nm}$ GaN DH-HEMTs with Re-Grown Ohmic," in Proc. 2010 IEEE Int. Electron Devices Meet., Dec. 2010, pp. 30.1.1-30.1.4.

[74] M. Micovic, A. Kurdoghlian, K. Shinohara, S. Burnham, I. Milosavljevic, M. Hu, A. Corrion, A. Fung, R. Lin, L. Samoska, P. Kangaslahti, B. Lambrigsten, P. Goldsmith, W. S. Wong, A. Schmitz, P. Hashimoto, P. J. Willadsen, and D. H. Chow, "W-band GaN MMIC with $842 \mathrm{~mW}$ output power at $88 \mathrm{GHz}$," in 2010 IEEE MTT-S Int. Microw. Symp. Dig., Anaheim, CA, Jun. 2010, pp. 237-240.

[75] M. Micovic, A. Kurdoghlian, K. Shinohara, S. Burnham, I. Milosavljevic, M. Hu, A. Corrion, W. S. Wong, A. Schmitz, P. Hashimoto, P. J. Willadsen, and D. H. Chow, "W-band GaN MMIC amplifiers," presented at the 2010 IEEE Lester Eastman Conf. High Performance De., Troy, New York, 2010.

[76] M. Micovic, A. Kurdoghlian, H. P. Moyer, P. Hashimoto, M. Hu, M. Antcliffe, P. J. Willadsen, W. S. Wong, R. Bowen, I. Milosavljevic, Y. Yoon, A. Schmitz, M. Wetzel, C. McGuire, B. Hughes, and D. H. Chow, "GaN MMIC PAs for E-band (71-95 GHZ) radio," in 2008 IEEE CSIC Symp. Dig., pp. 1-4.

[77] S. Masuda, T. Ohki, K. Makiyama, M. Kanamura, N. Okamoto, H. Shigematsu, K. Imanishi, T. Kikkawa, K. Joshin, and N. Hara, "GaN MMIC amplifiers for W-band transceivers," in Proc. 2009 Eur. Microw. Integr. Circuits Conf., Rome, Italy, Sep. 2009, pp. 443-447.

[78] A. Fung, J. Ward, G. Chattopadhyay, R. Lin, L. Samoska, P. Kangaslahti, I. Mehdi, B. Lambrigtsen, P. Goldsmith, M. Micovic, A. Kurdoghlian, K. Shinohara, I. Milosavljevic, and D. H. Chow, "Power combined Gallium nitride amplifier with 3 Watt output power at 87 GHz," in Proc. 22nd Int. Symp. Space Terahertz Technol., Tucson, AZ, Apr. 2011.

[79] J. Schellenberg, E. Watkins, M. Micovic, B. Kim, and K. Han, "W-band, $5 \mathrm{~W}$ solid state power amplifier/combiner," in 2010 IEEE MTT-S Int. Microw. Symp. Dig., Anaheim, CA, Jun. 2010, pp. 240-243.

[80] H. Wang, L. Samoska, T. Gaier, A. Peralta, H.-H. Liao, Y. C. Leong, S. Weinreb, Y. C. Chen, M. Nishimoto, and R. Lai, "Power-amplifier modules covering 70-113 GHz using MMICs," IEEE Trans. Microw. Theory Tech., vol. 49, pp. 9-16, Jan. 2001.

[81] M. Morgan, E. Bryerton, H. Karimy, D. Dugas, L. Gunter, K. Duh, X. Yang, P. Smith, and P. C. Chao, "Wideband medium power amplifiers using a short gate-length GaAs MMIC process," in 2009 IEEE MTT-S Int. Microw. Symp. Dig., Honolulu, HI, Jun. 2009, pp. 541-544.

[82] D. L. Ingram, Y. C. Chen, J. Kraus, B. Brunner, B. Allen, H. C. Yen, and K. F. Lau, "A $427 \mathrm{~mW}, 20 \%$ compact W-band InP HEMT MMIC power amplifier," in IEEE RFIC Symp. Dig., 1999, pp. 95-98. 
[83] L. Samoska, A. Peralta, M. Hu, M. Micovic, and A. Schmitz, "A 20 $\mathrm{mW}, 150 \mathrm{GHz}$ InP HEMT MMIC power amplifier module," IEEE Microw. Wireless Compon. Lett., vol. 14, no. 2, pp. 56-58, Feb. 2004.

[84] L. Samoska, E. Bryerton, M. Morgan, D. Thacker, K. Saini, T. Boyd, D. Pukala, A. Peralta, M. Hu, and A. Schmitz, "Medium power amplifiers covering $90-130 \mathrm{GHz}$ for the ALMA telescope local oscillators," in 2005 IEEE MTT-S Int. Microw. Symp. Dig., Jun. 2005, pp. 1583-1586.

[85] L. Samoska and Y. C. Leong, "65-145 GHz InP MMIC HEMT medium power amplifiers," in IEEE MTT-S Int. Microw. Symp. Dig. 2001, vol. 3, pp. 1805-1808.

[86] W. R. Deal, X. B. Mei, V. Radisic, M. D. Lange, W. Yoshida, P. Liu, J. Uyeda, M. E. Barsky, A. Fung, T. Gaier, and R. Lai, "Development of sub-millimeter-wave power amplifiers," IEEE Trans. Microw. Theory Tech., vol. 55, no. 12, pp. 2719-2726, Dec. 2007.

[87] I. Kallfass, P. Pahl, H. Massier, A. Tessmann, S. Koch, and T. Zwick, "A $200 \mathrm{GHz}$ monolithic integrated power amplifier in metamorphic HEMT technology," IEEE Microw. Wireless Compon. Lett., vol. 19, no. 6, pp. 410-412, Jun. 2009.

[88] A. Tessmann, A. Leuther, C. Schwoerer, and H. Massler, "Metamorphic $94 \mathrm{GHz}$ power amplifier MMICs," in 2005 IEEE MTT-S Int. Microw. Symp. Dig., Jun. 2005, pp. 1579-1582.

[89] K. J. Herrick, K. W. Brown, F. A. Rose, C. S. Whelan, J. Kotce, J. R. Laroche, and Y. Zhang, "W-band metamorphic HEMT with 267 $\mathrm{mW}$ output power," in 2005 IEEE MTT-S Int. Microw. Symp. Dig., Jun. 2005 , pp. $843-846$.

[90] H. Eisele, "State of the art and future of electronic sources at terahertz frequencies," Electron. Lett., vol. 46, no. 26, pp. s8-s11, Dec. 2010.

[91] S. P. Voinigescu, E. Laskin, I. Sarkas, K. H. K. Yau, S. Shahramian, A. Hart, A. Tomkins, P. Chevalier, J. Hasch, P. Garcia, A. Chantre, and B. Sautreuil, "Silicon D-band wireless transceivers and applications," in Proc. Asia-Pacific Microw. Conf., 2010, pp. 1857-1864.

[92] U. R. Pfeiffer, E. Ojefors, and Y. Zhao, "A SiGe quadrature transmitter and receiver chipset for emerging high-frequency applications at 160 GHz," in Proc. IEEE Int. Solid State Circuits Conf., Feb. 2010, pp. 416-417.
[93] E. Laskin, M. Khanpour, S. T. Nicolson, A. Tomkins, P. Garcia, A. Cathelin, D. Belot, and S. Voinigescu, "Nanoscale CMOS transceiver design in the 90-170 GHz range," IEEE Trans. Microw. Theory Tech., vol. 57, no. 12, pp. 3477-3490, Dec. 2009.

[94] M. Seo, B. Jagannathan, C. Carta, J. Pekarik, L. Chen, C. P. Yue, and M. Rodwell, "A $1.1 \mathrm{~V} 150 \mathrm{GHz}$ amplifier with $8 \mathrm{~dB}$ gain and $+6 \mathrm{dBm}$ saturated output power in standard digital $65 \mathrm{~nm}$ CMOS using dummy pre-filled microstrip lines," in IEEE Int. Solid-State Circuits Conf. Dig., Feb. 2009, pp. 484-485.

[95] J. May and G. M. Rebeiz, "High-performance W-band SiGe RFICs for passive millimeter-wave imaging," in Proc. IEEE Radio Freq. Integr. Circuits Symp. (RFIC), Boston, MA, Jun. 2009, pp. 437-440.

[96] G. M. Rebeiz, J. May, M. Uzunkol, W. Shin, O. Inac, and M. Chang, "Towards high-performance $>100 \mathrm{GHz}$ SiGe and CMOS circuits," in IEEE Int. Microw. Symp. Dig., 2010, pp. 1320-1323.

[97] J. Yuan, J. D. Cressler, R. Krithivasan, T. Thrivikraman, M. Khater, D. C. Ahlgren, A. J. Jospeh, and J. S. Rieh, "On the performance limits of cryogenically operated SiGe HBTs and its relation to scaling for terahertz speeds," IEEE Trans. Electron Devices, vol. 56, no. 5, pp. 1007-1019, May 2009.

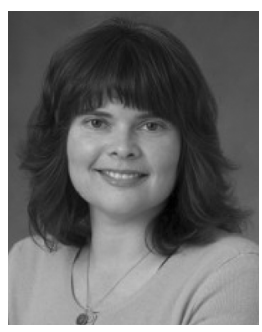

Lorene A. Samoska (M'95-SM'04) received the B.S. degree in engineering physics from the University of Illinois in 1989 and the Ph.D. degree in materials engineering from the University of California (UC), Santa Barbara, in 1995.

From 1995 until 1997, she was an Associate Research Engineer at the Electrical and Computer Engineering Department at UC, Santa Barbara, where she worked on the design and fabrication of state-ofthe-art InP HBT microwave digital circuits. In 1998 she joined the Jet Propulsion Laboratory, Pasadena, CA, where she is currently a Principal Engineer. Her research interests include the design and testing of .03-1 THz low noise radiometers and power amplifiers for local oscillator sources and transmitters in future space missions. 